\title{
ESPIRITUALIDAD EN ESTUDIANTES DE LA UNIVERSIDAD FEMENINA DEL SAGRADO CORAZÓN
}

\author{
SPIRITUALITY IN STUDENTS OF THE WOMEN'S UNIVERSITY OF THE \\ HOLY HEART
}

\author{
Elizabeth Bazán Gayoso rscj. ${ }^{1}$ \\ Fernando Elgegren Reátegui ${ }^{2}$ \\ Rosa Carrasco Ligarda ${ }^{3}$
}

\section{RESUMEN}

La investigación presenta un estudio sobre la orientación de la espiritualidad de las universitarias de la UNIFÉ. Se indaga sobre su formación religiosa, su aprehensión sobre el entorno social, la mirada que tienen sobre la vida y sus posibilidades futuras. Además, se presenta la percepción que tienen las estudiantes sobre sí mismas, su orientación espiritual y la gravitación de la familia. En síntesis, se presenta una aproximación al mundo personal de jóvenes que aspiran concretar sus objetivos a inicios del siglo XXI signado por cambios científicos y tecnológicos que deslumbran y mediatizan la relevancia de lo realmente importante: la relación con Dios, el encuentro con uno mismo y con los demás.

\section{Palabras clave}

Espiritualidad, creencia, Dios, autoconciencia, familia, realidad nacional, compromiso, ser joven

\section{ABSTRACT}

This research presents a study on the orientation of the spirituality of students of the Women's University of the Holy Heart. It explores on their religious training, their inderstanding of the social environment, their view on life and its future possibilities. In addition, it features the perceptions of students about themselves, their spiritual orientation and the importance of family. In short, it shows an approach to the personal world of young people aspiring to achieve their goals at the beginning of the 21st century, marked by dazzling scientific and technological changes that belittle the significance of what is really important: the relationship with God, the encounter with oneself and others.

\section{Keywords}

Spirituality, belief, God, self-awareness family, national reality, commitment, being young

\section{INTRODUCCIÓN}

El Centro de Investigación de la Universidad Femenina del Sagrado Corazón-UNIFÉ convoca hacia fines del 2013 a la realización de un estudio sobre la espiritualidad de las estudiantes universitarias.

1 Religiosa del Sagrado Corazón. Bachiller y Licenciada en Humanidades. Doctora en Educación por la Universidad Femenina del Sagrado Corazón. Actualmente Rectora de la Universidad Femenina del Sagrado Corazón (UNIFÉ)

2 Doctor en Filosofía y Sociólogo por la Pontificia Universidad Católica. Past Presidente de la Sociedad Internacional Tomás de Aquino Sección Perú. Past Director de la Escuela de Posgrado de la Universidad Femenina del Sagrado Corazón. Es docente Principal y ha tenido a su cargo la Dirección del Programa de Extensión Universitaria así como la Jefatura del Departamento Académico de Filosofía y Teología. Actualmente, se desempeña como Vicerrector Administrativo de la UNIFÉ.

3 Doctora en Filología por la Universidad Complutense de Madrid. Tiene tres maestrías. Directora del Centro de Investigación de la Universidad Femenina del Sagrado Corazón. Docente ordinaria de la UNIFÉ. 
El presente estudio es una aproximación a las posiciones que asumen las estudiantes con respecto a diferentes expresiones $\mathrm{O}$ dimensiones de la espiritualidad: la primera, mediante creencias, vivencias de la fe y las prácticas de espiritualidad; la segunda, a través de la formación y desarrollo de la personalidad, centrada en la autoconciencia-autonomía; la tercera, en las relaciones interpersonales y la cuarta, mediante opiniones que configuran representaciones sobre la sociedad peruana, la familia, la espiritualidad en sí, la religión y sobre el ser joven en nuestros días.

El estudio se articula en cinco capítulos. El planteamiento del problema de investigación está tratado en el primer capítulo en el que se describe la situación problemática, la justificación e importancia de la investigación, la formulación del problema y los objetivos.

El capítulo segundo sustenta el Marco Teórico mediante una breve revisión de la literatura pertinente, el señalamiento del antecedente que motiva el estudio y la exposición de las bases conceptuales. El tercer capítulo trata sobre la metodología en tanto se detalla el tipo, nivel y diseño de la investigación, la población y la muestra, las técnicas e instrumentos de recolección de la información y características de la muestra. En el cuarto capítulo se presenta los resultados, de acuerdo a los objetivos del estudio; y siguiendo las afirmaciones sobre las dimensiones de la espiritualidad, las opiniones respecto a la sociedad peruana, la familia, la espiritualidad, la de ser joven hoy y la religión. En el quinto capítulo se discute y analiza los resultados, relacionándolos e integrándolos en función de los objetivos.

\section{CAPÍTULO I}

\section{PLANTEAMIENTO DEL PROBLEMA DE INVESTIGACIÓN}

\section{Descripción de la situación problemática}

Junto al bienestar y las bondades traídas por la ciencia y la tecnología se han gestado nuevos enfoques para responder a interrogantes siempre abiertos a la mente humana. Asimismo, las conquistas del pensamiento van reforzando la conciencia de poder y autonomía del hombre actual de tal manera que este siente que puede controlar el mundo cada vez más, muy a pesar de las experiencias que muestran la irracionalidad a la que puede llegar el ser humano desbordado en genocidios, exterminios poblacionales y depredación del planeta.

El bienestar material, impactante en algunos espacios y grupos humanos, pero con grandes desequilibrios en otros, da la impresión de estar encontrando la ansiada felicidad en la posesión de cosas. La felicidad parece estar identificada con el tener y el disfrutar al punto que, satisfechos los "deseos inmediatos", no hay espacio psicológico para deseos más profundos.

Otro aspecto a tener en cuenta es la atracción que ejerce el mundo exterior en la persona; hay como una ruptura entre el mundo interior $y$ exterior, entre interioridad y exterioridad; parece muy difícil abrir un diálogo entre estas dimensiones.

El deslumbramiento de las cosas, imágenes, modelos, luz, color, aromas que se ofrecen, no deja espacio para encontrarse a sí mismo; de la misma manera el presentismo que suscita la rapidez de comunicación, para obtención de lo que solicitamos recorta la capacidad de "espera"; se quiere todo al momento, por lo que es difícil hacer cortes al activismo, darse espacio para el silencio, para la reflexión, para el propio conocimiento, para darse cuenta de lo que nos está pasando; por lo tanto, vivir el presente a como viene en su vorágine no da lugar para plantearse metas ni prioridades de algún tipo.

Estas, entre otras muchas situaciones reales, concretas, nos convierten en personas muy pragmáticas, individualistas, materialistas, con una visión del mundo, de la vida y de nuestra propia existencia sin horizontes. Esto va de la mano con la idea que Dios no hace falta, lo que puede unirse a una propuesta religiosa poco cercana a la vida y por lo tanto pierde su sentido. También se percibe cierto desencanto. 
Sin embargo, es evidente que las propuestas religiosas con acento riguroso también encuentran aceptación en grupos de jóvenes y cuyas razones convendría explorar.

Es necesario reconocer que de manera latente hay en muchos jóvenes inquietud por proyectarse en servicio a personas necesitadas, así como solidaridad, compasión, necesidad de encontrar sentido a su vida. En otros hay cierta atracción por lo misterioso, lo oculto, lo esotérico. Ciertos indicios de aspirar hacia lo transcendente.

Estando en contacto con jóvenes universitarias, que provienen de distintos contextos sociales, que traen formación previa de centros educativos particulares, algunas de ellas de entidades religiosas, otras de centros educativos estatales y municipales; unas de Lima, otras de provincias; con situación económica diversa, nos preguntamos si tienen en su vida un soporte espiritual que las ayuda afrontar los retos que ponen en cuestión su propia razón de ser, su intimidad y sus relaciones personales.

¿En qué consiste este soporte espiritual? ¿Hay una intuición y experiencia personal de Dios? ¿Cómo influye en su vida personal? ¿Influye en su relación con los otros? ¿Qué soportes espirituales tienen los jóvenes universitarios? ¿Son soportes espirituales religiosos? ¿Hacen referencia a Dios? ¿Cómo viven esta espiritualidad?

Para una mejor comprensión del alcance y sentido de las respuestas a estas interrogantes será necesario construir un perfil sobre la espiritualidad (creencia-fe-práctica) de las jóvenes universitarias, cómo se perciben a sí mismas en su desarrollo personal (autoconciencia) $y$ en sus relaciones interpersonales

Por otro lado, frente a la problemática planteada será necesario conocer y valorar lo que piensan las estudiantes de la UNIFÉ en relación a la realidad nacional, la familia, la religión, la espiritualidad en general y sobre el hecho de ser joven hoy.

\section{Justificación e Importancia de la Investigación}

Las respuestas a las preguntas formuladas en la descripción de la situación problemática serán de gran valor para todos los que estamos convencidos que la juventud es la forjadora del presente y futuro de la sociedad, que los jóvenes actualmente están desprotegidos porque pareciera que les falta soportes fuertes para resistir contracorrientes y emprender cosas grandes de manera sostenida. Del mismo modo, conocer las intuiciones de los jóvenes, sus aspiraciones profundas, vacíos o sueños, será de gran ayuda para revisar nuestras propuestas de formación.

\section{Formulación del Problema}

\subsection{Problema General}

¿Cómo perciben y expresan su espiritualidad las estudiantes universitarias del III al IX ciclo de estudios de la UNIFÉ?

\subsection{Problemas específicos}

1. ¿Cómo manifiestan las estudiantes universitarias su creencia-fepráctica?

2. ¿Cómo expresan las estudiantes universitarias su autosuficienciaautonomía?

3. ¿Cómo expresan su espiritualidad las estudiantes universitarias en sus relaciones interpersonales

4. ¿Cuál es la percepción de las estudiantes universitarias sobre la sociedad peruana, la familia, la espiritualidad, ser joven en nuestros días y la religión?

\section{Objetivos}

\subsection{Objetivo General}

Identificar cómo perciben y expresan su espiritualidad las estudiantes universitarias así como las características de las representaciones 
que construyen en relación a la sociedad peruana, la familia, la espiritualidad, la religión y la juventud.

\subsection{Objetivos específicos.}

4.2.1 Identificar el sentido ontológico de espiritualidad, manifestado en creencias, vivencias y prácticas de fe de carácter religioso.

\subsubsection{Caracterizar las expresiones psicológicas de la espiritualidad que perfilan un proceso de crecimiento y maduración de la personalidad.}

4.2.3 Describir la fenomenología de la espiritualidad manifestada en las vivencias interpersonales personales así como en las representaciones mentales sobre la sociedad peruana, la familia, la espiritualidad en sí, la religión y ser joven hoy.

\section{CAPÍTULO II}

\section{MARCO TEÓRICO}

\section{Revisión de la literatura}

Anthony James, estudiante graduado del Departamento de Desarrollo y Estudios de la Familia de la Universidad de Missouri, en Columbia (USA), presenta en junio de 2010, en Northwestern Black Graduate Student Association Conference, su Preliminary Finding on qualitative exploration of Children and youth's conceptualization spirituality. Este estudio busca determinar el impacto de la espiritualidad en el desarrollo positivo de los jóvenes, incluyendo la autoestima y el comportamiento pro-social, así como si la espiritualidad reduce los comportamientos juveniles negativos o de riesgo.

Según James, ante la pregunta "¿Qué significa ser un joven espiritual?, las respuestas describen el comportamiento espiritual en términos de 6 categorías relacionadas con el desarrollo personal y social. Ser espiritual engloba: 1. Tener un propósito; 2. Mantener vínculos con un poder superior, con otras personas y con la naturaleza; 3 . Tener una base de bienestar que incluya la alegría y la plenitud, la energía y la paz; 4. Tener una firme convicción; 5. Tener confianza en sí mismo; 6. Tener un impulso para la virtud, es decir, tener la motivación para hacer lo correcto y decir la verdad.

James añade una séptima categoría: "incapaz de definir" que incluye respuestas del tipo "no estoy seguro" o "no se" de quienes se definen espirituales pero que no podían explicar en qué consiste toda vez que la espiritualidad no es un concepto fácil de articular y definir.

James encuentra también que a las personas les cuesta separar espiritualidad de religión; sin embargo, las diferencias entre ambas son importantes para comprender el comportamiento y el desarrollo individual.

La Federación Internacional de Estudiantes Evangélicos en Europa-IFES, da cuenta de un estudio hecho entre el 2011 y 2012 por 5 organizaciones afiliadas en Bélgica, Portugal, Croacia, Albania y Rumanía sobre espiritualidad a base del "Sondeo Europeo de Valores" (SEV 2008), una herramienta estandarizada de libre acceso y del cual se seleccionó un set centrado sobre cómo viven los estudiantes su espiritualidad. Contestaron el cuestionario unos 200 estudiantes universitarios en cada uno de los cinco países. El cuestionario incluía ítems sobre familia, trabajo, amigos, religión y descanso (tiempo libre).

Cabe destacar entre las conclusiones del estudio que los estudiantes europeos creen mantener el control sobre sus vidas; rechazan la religiosidad tradicional pero se consideran espirituales; no creen que haya un bien y un mal absolutos aunque sí confían mayoritariamente en la existencia de algún tipo de divinidad. Por lo demás, la familia sigue siendo lo más valioso en la vida: $91 \%$ en Albania; superior al $85 \%$ en Croacia, Portugal y Rumanía. En Bélgica la familia se ve superada en importancia por los amigos (75\%). El trabajo y el tiempo libre tienen un segundo nivel de prioridad. La 
religión solo es importante entre estudiantes de Rumanía (42\%), por delante de los amigos. La mayoría siente tener capacidad de tomar decisiones libremente y controlar su propia vida. En cuestiones más relacionadas con la visión moral de sus vidas, el $47 \%$ postula un relativismo moral que se hace extensivo también a la religión: "no existe una religión verdadera, pero todas las grandes religiones contienen alguna verdad básica". No se practica la religión pero sí se ora; la mayoría no asiste a actos religiosos, pero sí tienden más a la oración cuando están solos.

Considerando la importancia que tiene la familia para los encuestados, el estudio anima a valorar a una evangelización más comunitaria y relacional.

Josué Edison Turpo Chaparro (2011), en Espiritualidad y rendimiento académico: un estudio comparativo entre alumnos internos y alumnos externos de la Universidad Peruana Unión, presenta como objetivo general explorar los comportamientos más notorios que se observan al establecer el grado de asociación entre las variables de hábitos de estudio, rendimiento académico y espiritualidad de los alumnos internos y externos de la Universidad Peruana Unión de Tarapoto. La muestra estuvo conformada por 152 estudiantes de cinco diferentes carreras. Se aplicaron dos cuestionarios uno para obtener información sobre espiritualidad y el otro para evaluar los hábitos de estudio de los estudiantes. En los resultados no se halló correlación entre las variables estudiadas, pero sí había diferencia significativa a favor de los alumnos internos frente a los externos.

La investigación de Walter Arias; María Alejandra Masías; Emmanuel Muñoz y Mayumi Arpasi (2013) Espiritualidad en el ambiente laboral y su relación con la felicidad del trabajador Universidad Católica San Pablo, Arequipa, Perú, tiene como objetivo general demostrar la relación entre la espiritualidad y la felicidad en un contexto laboral. La muestra representativa fue de 72 trabajadores (24 administrativos y 48 docentes) de la referida Universidad. Se les aplicó el Cuestionario de Espiritualidad en el Trabajo, así como la
Escala de Felicidad de Lima. Resultados: se encontraron altos niveles de espiritualidad en los administrativos y los profesores, además de relaciones estadísticamente significativas entre la espiritualidad y el sexo, el sexo y la realización personal, así como entre el estado civil y la satisfacción con la vida y la realización personal en los trabajadores administrativos, mas no en el personal docente. En general, las relaciones entre espiritualidad y felicidad son mayores y más fuertes entre los trabajadores administrativos que entre los profesores.

Sandra Morales Arroyo (2014) en su investigación sobre la Relación entre la espiritualidad, el bienestar físico y el bienestar psicológico de los estudiantes universitarios (Pontificia Universidad Católica de Puerto Rico) presenta como objetivo general determinar la relación entre la espiritualidad, el bienestar físico y el bienestar psicológico de los estudiantes de primer año que estudian en dos universidades de la región oeste de Puerto Rico. La muestra de estudio estuvo conformada por 387 estudiantes de primer año de universidad: 181 estudiantes de la Pontificia Universidad Católica de Puerto Rico y 206 estudiantes de la Universidad Interamericana de Puerto Rico. Se les aplicó un cuestionario sobre espiritualidad, bienestar físico y bienestar psicológico. Los resultados evidenciaron una correlación positiva media entre las variables de estudio. Se encontraron diferencias significativas entre el nivel de Espiritualidad de las mujeres respecto a los varones. Revista Griot (ISSN 1949-4742) Volumen 7, Número. 1, Noviembre 2014.

\section{Antecedente}

En setiembre de 2013 tuvo lugar en la Universidad Buenaventura de Colombia el Segundo Seminario Taller de la Red de Investigadores de la Diversidad Religiosa y de las Culturas en América Latina y el Caribe, en el que participaron representantes de Universidades de Perú, Uruguay, Ecuador, Chile, España y Colombia.

La Universidad Femenina del Sagrado Corazón -UNIFÉ- estuvo representada por la Directora del Centro de Investigación, Dra. Rosa Sonia 
Carrasco Ligarda, quien expuso sobre "La investigación interdisciplinaria e internacional", teniendo en consideración que el objetivo central estaba orientado a "consolidar de manera colaborativa, sucesiva y prospectiva, la Red de Investigadores de la diversidad religiosa y de las culturas en América Latina y el Caribe, a través de un ejercicio académico-virtual de elaboración de proyectos de investigación, útiles para estudiar y comprender el campo religioso, su diversificación y consecuentes demandas dirigidas al trabajo interdisciplinar, interinstitucional y transnacional"

Los temas de las conferencias como "La investigación religiosa en Colombia", "La diversidad religiosa y las culturas" y "Cómo se trata el tema de la diversidad religiosa mundialmente y cuáles son las agendas de investigación continentales", sirvieron de marco para acordar por consenso en mesas de trabajo la elaboración de una investigación interdisciplinar e internacional sobre las búsquedas espirituales de los estudiantes universitarios.

La Dirección de Investigación de la Universidad asumió el compromiso de llevar adelante lo acordado conformando un equipo multidisciplinario, que en reuniones semanales comenzaron a intercambiar ideas para dar forma y contenido al estudio.

\section{Bases conceptuales}

"Ser hombre, afirma Lobato (1997), es caminar en la vida de la inteligencia" (p.92), pero también es un andar en la vida de todo su ser, en el modo de entender y vivir la corporeidad, las relaciones interpersonales, la historia personal y social, la apertura a un Ser Trascendente. Ello implica la autoconciencia, el dominio de sí mismo, la autodeterminación de lo que libremente uno decide ser como presencia de sí mismo, ante sí, ante los seres de la naturaleza y ante otras personas, en su mundo de relaciones. Bien dice Lobato que "la nobleza del hombre le viene de su espiritualidad" (p.80).

De Fiores y Goffi (1983), al presentar el Nuevo Diccionario de Espiritualidad, señalan que hoy en día es muy necesaria una espiritualidad que motive la vida cotidiana; que el hombre actual no se resigna a una vida cerrada en el tiempo, sin horizontes y sin esperanzas, toda vez que se siente empujado a tomar decisiones frente a diferentes opciones de vida. Decidir, en primer lugar, por la espiritualidad como actitud orientadora, decisiva y unificadora o por una vida mediocre, reducida a una cadena superficial de acciones desprovistas de significado. En segundo lugar, puede optar por una espiritualidad como escucha del Espíritu que habita en el hombre o por el confinamiento en el universo material y en el torbellino de la técnica sin alma de una sociedad consumista. En tercer lugar, puede decidir ente una espiritualidad como encuentro vivo con Cristo, fuente de libertad, comunión y vida eterna o la condena al absurdo y a la desesperación.

Segundo Galilea (1989) en El camino de la espiritualidad plantea que si bien la palabra espiritualidad ha caído en sospecha, sin embargo hoy en día se habla más de la misma en medios cristianos, particularmente en América Latina, en donde se ha venido presentando la renovación pastoral, teológica, institucional de la Iglesia. "La espiritualidad - afirma Galilea - no es una ciencia o una praxis más en la Iglesia. Es la savia de la pastoral, de la teología y de la comunidad, cualquiera que sea su modelo" (p.19)

A lo largo del presente estudio se sostiene que la espiritualidad de lo humano se descubre primero en la constitución ontológica de la persona (como ser ontológico); segundo, en el desarrollo de su personalidad (como ser psicológico) y tercero, en la fenomenología de sus relaciones con la naturaleza y con otras personas (como ser relacional).

La espiritualidad de la persona como manifestación ontológica se fundamenta en la subsistencia y la unicidad de su ser así como en su apertura a Dios.

En este sentido Elizabeth Bazán (2008) afirma que "la espiritualidad es una manera 
ser y de vivir, abiertas al espíritu de Dios que dinamiza la totalidad de la persona y la historia" (p. 59).

Si como señala Tomás de Aquino en la Suma Teológica $(\mathrm{I} .29,3)$ que la persona es la realidad más digna de cuantas existen, lo es justamente por su naturaleza espiritual, con la cual sella la libertad que le es propia en cuanto autodominio y orientación hacia el fin debido. La condición ontológica espiritual del hombre posibilita su gran apertura hacia Dios, el cosmos y el mundo de las personas.

Lucas (1999) sustenta que la apertura del hombre a Dios es la constitución fundamental del hombre. Es la condición que hace que el hombre sea lo que es, puede aceptarla o rechazarla. "La espiritualidad del hombre - afirma- es positividad: un Yo, una persona que existe como sujeto único $e$ inconfundible abierto a un Tú que también es persona" (p.293). "La persona se constituye fundamentalmente como un ser que existe en sí mismo y está abierto al SER ABSOLUTO" (p.294)

Según Lobato la palabra "espiritualidad" causa cierto rechazo porque está cargada de muchos significados; sin embargo, hay que reconocer que su significado de uso prevalente es "para designar la vida de las relaciones del hombre con Dios, de los modos de traducir esa relación en la historia de la pietas" (p.80)

La espiritualidad de la persona en su manifestación psicológica se entiende como principio de actividades con las que va moldeando y desarrollando su personalidad. Los filósofos de la modernidad insisten en la subjetividad del hombre. La espiritualidad de la persona es examinada desde su interioridad, desde su conciencia, tanto que algunos llegan a concebir la persona solo como un orden estructurado de actos de conciencia en los que se realiza continuamente a sí misma, según la identificación que hace Lucas (1999) con respecto a los representantes y principios generales de la teoría actualista.
El mismo Lucas sostiene que la persona tiene un significado ontológico que la constituye como existente a título propio, por sí y en sí, pero, asimismo existe una constitución psicológica en cuanto consciente de sus actividades. "Cuando hablamos de constitución psicológica de la persona-afirmanos referimos al mismo ente sustancial humano, en cuanto 'consciente' de sus actividades....; para indicar la constitución psicológica se utiliza el término 'Yo' o bien 'sujeto psíquico" (p.270). "El Yo se descubre como Yo, como sujeto autoconsciente, allí donde el objeto de conocimiento es el Yo mismo..." (p.271). Es pertinente puntualizar con Lucas que la autoconciencia concebida como la capacidad del sujeto de volver sobre sí mismo, 'es un acto inmaterial y espiritual' (p.139)

Además, añade Lobato (1997) "La condición espiritual de la forma humana lleva consigo la exigencia de libertad. En ella va implicada no solo la autoconciencia, sino el dominio de sí mismo para ejercer la autodeterminación. El ser espiritual tiene una circularidad por la presencia de sí a sí mismo" (p.93). En la perspectiva de Lobato desde la personalidad se puede observar la más alta excelencia de lo humano, su singularidad única e irrepetible, su valor de fin y su apertura ilimitada.

Finalmente, la espiritualidad de la persona se manifiesta en las formas de expresión de su ser relacional con el universo social y el mundo físico natural. Lo que uno es en lo más íntimo, las potencialidades y limitaciones individuales, se develan y descubren en la convivencia con la naturaleza y las personas. Por su misma condición de ser natural la persona forma parte de un único universo en el que vive y se desarrolla como humano a la par que convive comunicándose en diferentes redes sociales.

Comoloreconoce Lucas (1999) en la sociedad "se desarrollan los valores más sublimes de la vida personal espiritual: el conocimiento y el amor... Darse espiritualmente no es empobrecerse sino enriquecer el propio ser hombre" (p.249). La persona descubre $y$ enriquece su ser espiritual en el modo 
de posicionarse en la naturaleza y en su convivir diario.

Vásquez Borau (1997) subraya las siguientes notas de la espiritualidad formuladas por E. Mounier, fundador del Personalismo: la persona sumergida en la naturaleza traspasa a la misma, se personaliza comunicándose, puede conseguir la libertad y se realiza en el compromiso, en la acción.

Javier Garrido (1988) precisa que "personalizar quiere decir que algo que hasta el momento no era 'tuyo' lo haces 'tuyo'" (p.19). Luego añade que "el sentido de la vida no se aprende en la comunicación ideológica. Se respira desde niño, al contacto con las personas que nos aman y educan, según las actitudes básicas que uno va adoptando" (p.23).

La presente investigación explora la espiritualidad de las estudiantes de la UNIFÉ en relación a su apertura a una realidad que sobrepasa la conciencia personal. Espiritualidad expresada en creencias, en diferentes maneras de experimentar y vivir fe $y$ en prácticas que caracterizan a las estudiantes universitarias en relación a lo divino o trascendente.

Podríamos afirmar también que la espiritualidad de la persona se define por su peso ontológico $y$ por su peso psicológico en tanto presencia en sus actos y modos de ser persona, en el desarrollo de su personalidad.

Es pertinente advertir que al enfocar la espiritualidad en perspectiva psicológica se corre el riesgo de reducir la vida espiritual a estados de conciencia. Como señala Garrido (1988) "Vivimos una época en que la racionalidad práctica (el arte de relacionar medios y fines) ha penetrado incluso en lo religioso. Peligro de confundir la experiencia de la fe con el proceso de autoconciencia" (p.9).

En la investigación sobre espiritualidad de mujeres universitarias se da un peso especial a elementos estructurales de la personalidad de las estudiantes en relación al modo como la vida es entendida y vivida. Sin embargo, a fin de no caer en un mero psicologismo, se ha cuidado que en las afirmaciones relacionadas con la autoconciencia y autonomía se tome en consideración la intencionalidad u objeto sobre el cual está orientada y centrada la personalidad de la estudiante.

La idea de espiritualidad entendida como la apertura de la persona en el orden del ser ontológico, del ser psíquico y del ser relacional lo sintetiza magistralmente Lobato (1997) cuando afirma que "la persona puede conocer; y se abre lo mismo que el ente, conoce lo otro y se conoce a sí misma. Puede salir de sí y amarse y amar a las personas por sí mismas, y todo lo demás en orden a las personas". (p.112)

\section{CAPÍTULO III}

\section{METODOLOGÍA}

\section{El tipo, nivel y diseño de la investigación}

El presente estudio de investigación es de tipo aplicado porque tiene por finalidad la búsqueda y consolidación del saber y la aplicación de los conocimientos para el enriquecimiento del acervo cultural (Cazau, 2006), así como resolver un determinado problema o planteamiento específico.

Es de nivel descriptivo por que se selecciona una serie de conceptos o variables con el fin de describirlas. Estos estudios buscan especificar las propiedades importantes de personas, grupos, comunidades o cualquier otro fenómeno. El énfasis está en determinar cómo es o cómo se manifiesta el fenómeno (Cazau, 2006), cuyo diseño es descriptivo explicativo ya que trata de evaluar las diferentes percepciones de la estudiantes universitarias.

\section{Población y muestra}

La población total de estudio fue de 2,007 estudiantes de pregrado matriculadas en el semestre agosto-diciembre de 2014, pertenecientes al III al IX ciclo de estudios. La muestra seleccionada fue de $757(31,1 \%)$ la que se obtuvo a través de un muestreo estratificado (Tabla 01) 
Tabla 01. Distribución de la muestra

\begin{tabular}{|l|cccc|}
\multicolumn{1}{c}{} & Ni & $\mathrm{f} \%$ & $\mathrm{ni}$ & $\mathrm{f}$ \\
\hline Psicología & 514 & $26 \%$ & 188 & $25 \%$ \\
Educación & 330 & $16 \%$ & 169 & $22 \%$ \\
Nutrición & 207 & $10 \%$ & 54 & $7 \%$ \\
Traducción & 236 & $12 \%$ & 63 & $8 \%$ \\
Ciencias de C. & 117 & $6 \%$ & 43 & $6 \%$ \\
Arquitectura & 243 & $12 \%$ & 100 & $13 \%$ \\
Derecho & 157 & $8 \%$ & 51 & $7 \%$ \\
Adm.Neg. Int. & 203 & $10 \%$ & 89 & $12 \%$ \\
TOTAL & 2007 & $100 \%$ & 757 & $100 \%$ \\
\hline
\end{tabular}

\section{Técnicas $e$ instrumentos recolección de la información}

La técnica utilizada fue una encuesta y el instrumento un cuestionario elaborado por los investigadores el que se denominó CUESTIONARIO SOBRE ESPIRITUALIDAD aplicado a estudiantes del III al IX ciclos de las carreras de Psicología, Educación Inicial, Educación Especial, Educación Primaria, Nutrición y Dietética, Traducción e Interpretación, Ciencias de la Comunicación, Arquitectura, Derecho y Administración de Negocios Internacionales.

El Cuestionario sobre Espiritualidad consta de 75 items, los cuales fueron divididos en tres dimensiones:

\section{Dimensión ontológica (creencia-fe-} práctica): necesidad de trascendencia; identificación de su contenido; sentido de la creencia y fe; valoración de la creencia-fe en la vida personal y social; posición frente a ciencia-fe; diferenciación e identificación conceptual de prácticas espirituales y religiosas; descripción de prácticas espirituales y religiosas personales; necesidades espirituales. Esta dimensión comprende los ítems:

Creencia (I. 1-8-10-23)

Vivencia de la Fe (I. 2-7-9-24)

Práctica (I. 3-4-5-6-11-19)
Dimensión psíquica (autoconcienciaautonomía): desarrollo de la personalidad; toma de decisiones desde referentes de valor; esfuerzo por crecer en libertad y por amar cada vez mejor; valoración de la vida desde la concepción; satisfacción consigo misma; valoración de sí misma. Comprende los ítems: I.15-18-22-25; II.1- 2-3-4-6-7-10-12-13-1415-16-19-21-22-23-25 y III.9-10-11

\section{Dimensión relacional (fenomenológica):} relaciones interpersonales; apreciación sobre los problemas humanos actuales; actitudes frente a los problemas; configuración de escala de valores personales; actitudes hacia grupos tradicionalmente excluidos; actitudes hacia grupos religiosos. Comprensión y posicionamiento sobre inclusión social; auto percepción de carencias relacionales; participación en grupos / organizaciones y compromisos sociales. Cuidado de la naturaleza. Representaciones sociales sobre la sociedad peruana, la familia, la espiritualidad, la religión y ser joven en nuestros días. Incluye todos los ítems restantes. Comprende los ítems: I.12-13-14-16-17-20-21; II.5-8-9-11-17-1820-24 y III.1-2-3-4-5-6-7-8-14-17-18-21.

\section{Características de la muestra}

La participación de las estudiantes ha sido voluntaria y con las garantías de confidencialidad y resguardo de la información. 
El Cuestionario ha sido aplicado en aula por los docentes en sitio de diferentes asignaturas, en el tiempo de una semana de clases.

El Cuestionario de Espiritualidad incluye datos generales de orden académico y socio- demográficas: carrera profesional y ciclo que estudia, edad, colegio de estudios secundarios de procedencia, estado civil, religión, persona con quien vive, trabajo, otros estudios superiores, financiamiento de estudios $y$ pertenencia a organizaciones.

\section{CAPÍTULO IV}

\section{RESULTADOS DE LA INVESTIGACIÓN}

Se presenta el análisis descriptivo en primer lugar del perfil socio demográfico de las entrevistadas, en segundo término de las dimensiones de la espiritualidad y en tercer lugar de lo que se piensa sobre la sociedad peruana, la familia, la espiritualidad, el ser joven hoy y la religión.

\section{Perfil socio demográfico}

Respecto a las carreras profesionales que estudian las encuestadas, el $25 \%$ es de psicología, seguidas por las educación (22\%), Arquitectura (13\%), Administración de Negocios Internacionales (12\%), Traducción e Interpretación (8\%), Nutrición y Dietética (7\%) Derecho (7\%) y Ciencias de la Comunicación (6\%). (tabla 02 y gráfico 01 )

Tabla 02. Distribución de estudiantes por Carrera Profesional

\begin{tabular}{ccc}
\hline Carrera Profesional & $\mathrm{F}$ & $\mathrm{f} \%$ \\
\hline Psicología & 188 & 24,8 \\
Educación & 169 & 22,3 \\
Nutrición y Dietética & 54 & 7,1 \\
Traducción e Interpretación & 63 & 8,3 \\
Ciencias de la Comunicación & 43 & 5,7 \\
Arquitectura & 100 & 13,2 \\
Derecho & 51 & 6,7 \\
Adm. Negocios Internacionales & 89 & 11,8 \\
\hline
\end{tabular}

\section{Gráfico 01.}

\section{Carreras Profesionales}
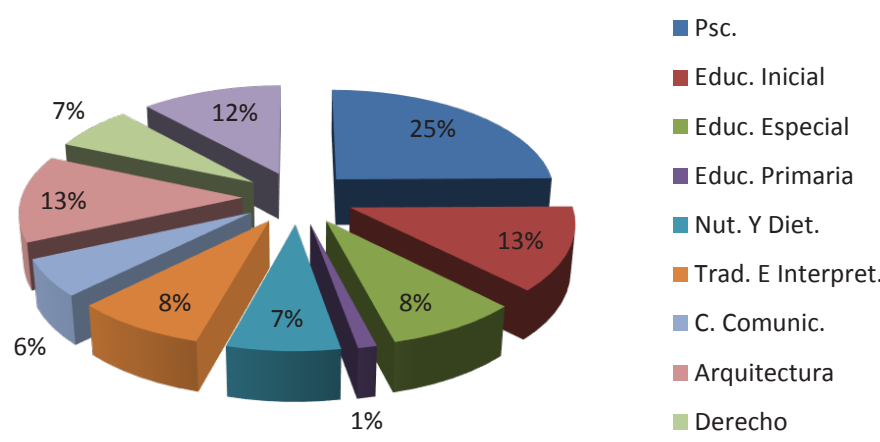

Adm. Neg. Inter. 
En relación al colegio de procedencia el $48 \%$ es de una entidad educativa particular, el 37\% es de colegio público estatal y el $15 \%$ proviene de colegio parroquial (tabla 03 y gráfico 02 ).

Tabla 03. Distribución de estudiantes por tipo de Colegio

\begin{tabular}{lll} 
Tipo de Colegio & $\mathrm{f}$ & $\mathrm{f} \%$ \\
Parroquial & 114 & 15,06 \\
Particular & 360 & 47.56 \\
Público & 283 & 37,38 \\
\hline & 757 & 100 \\
\hline
\end{tabular}

\section{Gráfico 02.}

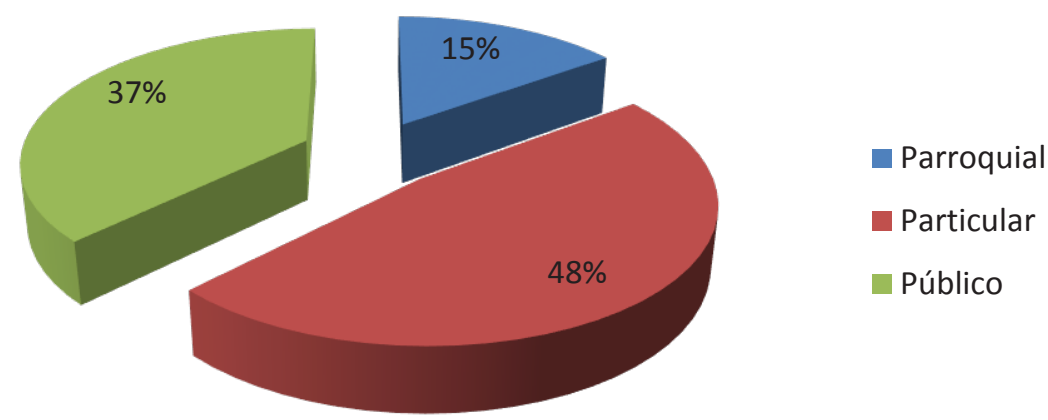

Con respecto al estado civil de las encuestadas, el $94 \%$ de ellas es soltera, el $3 \%$ es casada, el $2 \%$ es conviviente y menos del $1 \%$ es divorciada o separada (tabla 04 y gráfico 03 )

Tabla 04. Estudiantes según estado civil

\begin{tabular}{lcc} 
Estado Civil & $\mathrm{f}$ & $\mathrm{f} \%$ \\
Casada & 20 & 2,64 \\
Conviviente & 18 & 2,38 \\
Divorciada & 4 & 0,53 \\
Separada & 2 & 0,26 \\
Soltera & 713 & 94,19 \\
\hline Total & 757 & 100,00 \\
\hline
\end{tabular}

Gráfico 03.

\section{Estado Civil}

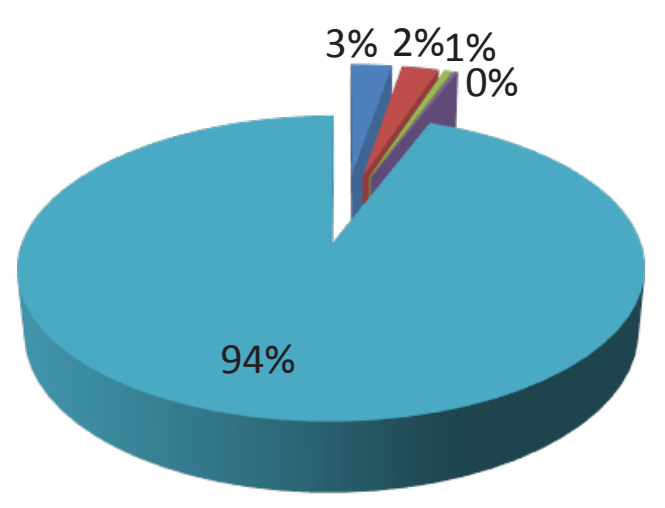


En cuanto a profesar una religión el $78 \%$ declara ser católica, el $12 \%$ es cristiana no católica y el $2 \%$ es de otra religión a las señaladas. El $8 \%$ no profesa religión alguna (tabla 05 y gráfico 04)

Tabla 05. Distribución de las Estudiantes por Religión

\begin{tabular}{lcc}
\hline Estudiantes por Religión & $\mathrm{f}$ & $\mathrm{f} \%$ \\
Católica & 594 & 78,5 \\
Cristiana No Católica & 93 & 12,3 \\
Otra & 13 & 1,7 \\
Ninguna & 57 & 7,5 \\
Total & 757 & 100,0 \\
\hline \hline
\end{tabular}

Gráfico 0.4

Estudiantes por tipo de Religión

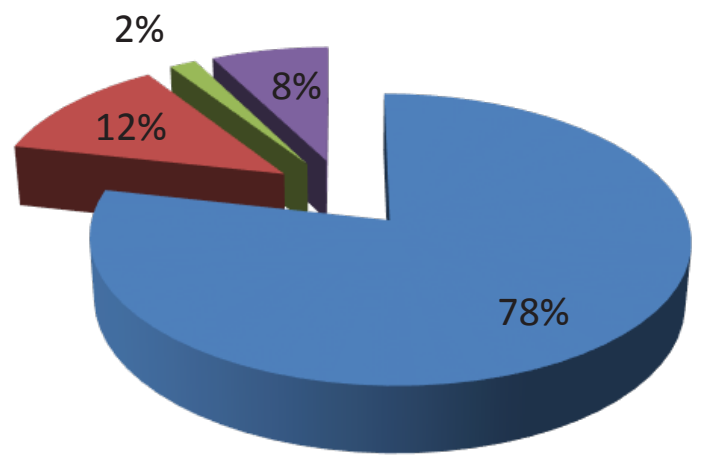

- Católica

Cristiana No Católica

Otra

Ninguna

En la tabla 06 y gráfico 05 se aprecia que el $53 \%$ vive junto con sus padres, el $19 \%$ con la madre, el $17 \%$ con familiares, el $5 \%$ vive sola, $3 \%$ vive con el padre, el $2 \%$ con el esposo y en la misma proporción con la pareja.

Tabla 06. Distribución de las Estudiantes por persona con quién vive

\begin{tabular}{lcc}
\hline Distribución de estudiantes & & \\
Persona con quién vive & $\mathrm{f}$ & $\mathrm{f} \%$ \\
Ambos Padres & 401 & 52,9 \\
Sola & 35 & 4,6 \\
Esposo & 13 & 1,7 \\
Familiares & 126 & 16,6 \\
Madre & 143 & 18,9 \\
Padre & 26 & 3,4 \\
Pareja & 14 & 1,9 \\
\hline Total & 757 & 100,00 \\
\hline
\end{tabular}




\section{Gráfico 05.}

\section{Personas con quién vive}
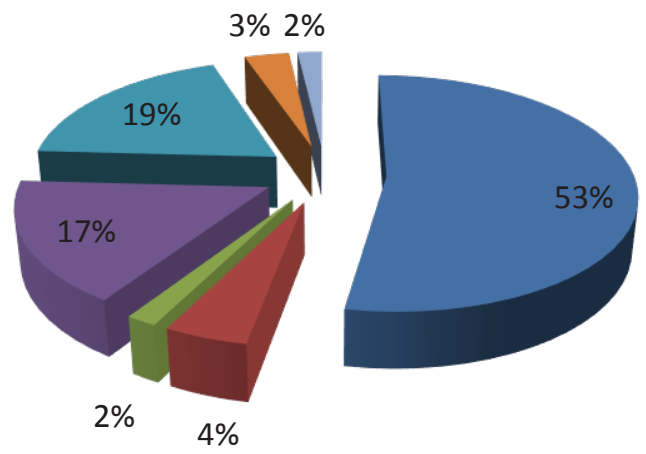
Ambos Padres
- Sola
Esposo
- Familiares
- Madre
Padre
- Pareja

Respecto a la situación laboral de las encuestadas, el 80\% no trabaja (tabla 07 y gráfico 06)

Tabla 07. Distribución de las Estudiantes por situación Laboral

$\begin{array}{llc}\text { Situación Laboral } & \text { F } & \text { f\% } \\ \text { Trabaja } & 150 & 19,82 \\ \text { No trabaja } & 607 & 80,18 \\ \text { Total } & 757 & 100,00\end{array}$

\section{Gráfico 06.}

\section{Estudiantes según situación Laboral}

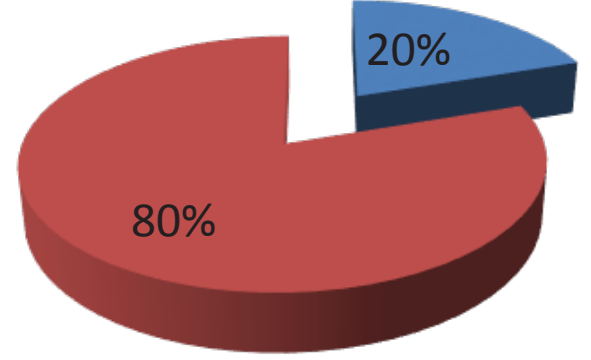

Trabaja

No trabaja

La tabla 08 y gráfico 07 muestran que el $87 \%$ de las participantes en la investigación señalan seguir estudios superiores únicamente en la Unifé.

\section{Tabla 08. Distribución de las estudiantes por estudios superiores}

\begin{tabular}{llr} 
Estudios Superiores & F & \multicolumn{1}{c}{ f\% } \\
En otro Centro Superior & 101 & 13,34 \\
Sólo en UNIFE & 656 & 86,66 \\
Total & 757 & 100,00
\end{tabular}




\section{Gráfico 07}

\section{Estudiantes por estudios Superiores}

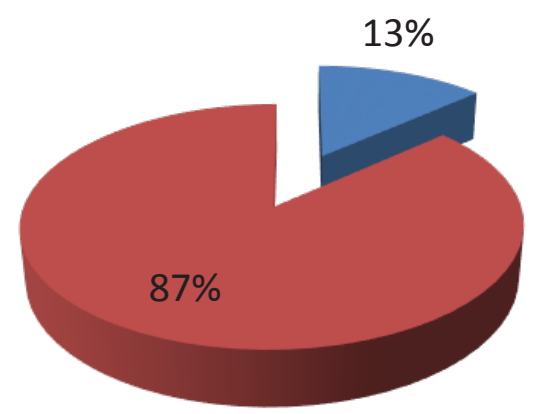

En otro Centro Superior

Sólo en UNIFE

Se aprecia asimismo que para el $40 \%$ son ambos padres los que financian los estudios profesionales de las entrevistadas, seguido del padre únicamente en un $31 \%$ o solo por la madre en un $17 \%$. En un $6 \%$ es el esposo (2\%), algún familiar (2\%) u otro (2\%). El $5 \%$ de las encuestadas especifica ser ella misma la que financia sus estudios. (tabla 09 y gráfico 08)

\begin{tabular}{lrr} 
Financiamiento de estudios & \multicolumn{2}{c}{$\mathrm{F}$} \\
Ambos Padres & 304 & 40,16 \\
Autofinanciamiento & 39 & 5,15 \\
Esposo & 14 & 1,85 \\
Familiares & 18 & 2,38 \\
Madre & 130 & 17,17 \\
Padre & 238 & 31,44 \\
Otro & 14 & 1,85 \\
\hline Total & 757 & 100,01 \\
\hline
\end{tabular}

\section{Gráfico 08}

\section{Estudiantes por financiamiento}

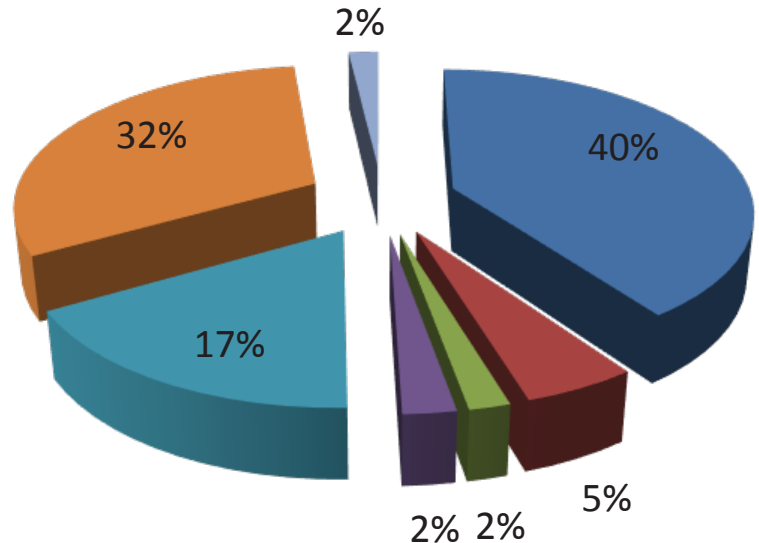

Ambos Padres

Autofinanciamiento

Esposo

Familiares

Madre

Padre

Otro 
En cuanto a pertenecer a una organización o grupo social el $48 \%$ no identifica alguna pertenencia; el 13\% forma parte de grupo de voluntariado; el $8 \%$ pertenece a algún club social; el $8 \%$ también a un grupo parroquial y asimismo el $8 \%$ declara pertenecer a algún grupo religioso; el resto identifica pertenencia a grupo estudiantil $(5 \%)$, grupo deportivo $(4 \%)$, grupo político $(2 \%)$ y otras (4\%) (tabla 10 y gráfico 09)

Tabla 10. Distribución de las Estudiantes por pertenecer a una organización o grupo social.

\begin{tabular}{lll} 
Organización o Grupo Social & f & f\% \\
Club Deportivo & 30 & 3,9 \\
Club Social & 62 & 8,2 \\
Grupo estudiantil & 39 & 5,2 \\
Grupo Parroquial & 60 & 7,9 \\
Grupo Político & 12 & 1,6 \\
Grupo religioso & 60 & 7,9 \\
Grupo Voluntario & 98 & 12,9 \\
Otras & 30 & 3,9 \\
Ninguno & 336 & 48,4 \\
\hline Total & 757 & 99,9 \\
\hline \hline
\end{tabular}

Gráfico 09

Estudiantes por Organización o Grupo Social

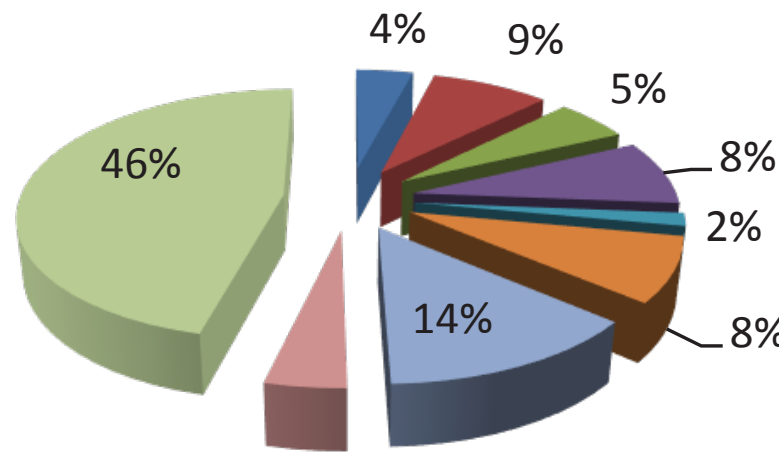

$4 \%$
Club Deportivo

- Club Social

Grupo estudiantil

Grupo Parroquial

- Grupo Político

Grupo religioso

A base de la información socio demográfica se puede afirmar que las estudiantes participantes en el estudio sobre espiritualidad se caracterizan por ser mayormente solteras en estado civil, sin ocupación laboral y que viven con sus padres, de quienes dependen económicamente para seguir sus estudios universitarios. Son católicas e identifican escasa pertenencia a organizaciones y grupos sociales.

\section{Sobre las dimensiones}

Se presenta como resultado la descripción por cada una de las dimensiones investigadas. Se considera como logro en la dimensión la suma de "siempre" y "casi siempre". El 70\% es el criterio para determinar si la dimensión obtuvo un nivel de logro importante, a la vez que se destacan el o los ítems relevantes. 


\subsection{Dimensión ontológica (creencia-fe-práctica)}

\section{Creencia}

La dimensión ontológica evaluada por los ítems de creencia arrojó los resultados que se indican a continuación:

Tabla 11. CREENCIA:

\begin{tabular}{|l|c|c|c|}
\hline \multicolumn{1}{c}{ Ítems } & A Veces & \multicolumn{1}{c}{ Casi Siempre } & Siempre \\
\hline 1. Necesito de Dios, de alguien trascendente & $15,9 \%$ & $18,2 \%$ & $61,4 \%$ \\
\hline $\begin{array}{l}\text { 8. Dios, en quien creo, es misericordioso y } \\
\text { compasivo }\end{array}$ & $5,6 \%$ & $8,7 \%$ & $81,2 \%$ \\
\hline $\begin{array}{l}\text { 10. Tengo clara conciencia de que Dios conduce mi } \\
\text { vida }\end{array}$ & $14,8 \%$ & $18,1 \%$ & $60,2 \%$ \\
\hline 23. Mi fe me ayuda a decidir quién soy & $19,6 \%$ & $31,8 \%$ & $43,2 \%$ \\
\hline Promedio & $13,9 \%$ & $19,2 \%$ & $61,5 \%$ \\
\hline
\end{tabular}

De acuerdo con la tabla 11 las creencias en Dios alcanzan un nivel de logro importante en 80,7\%, destacando el ítem "Dios, en quien creo, es misericordioso y compasivo" (81,2\% siempre)

\section{Vivencia de la fe}

Los ítems de vivencia de la fe dan cuenta de los siguientes porcentajes:

Tabla 12. VIVENCIA DE LA FE

\begin{tabular}{|l|c|c|c|}
\hline \multicolumn{1}{c}{ Ítems } & A Veces & \multicolumn{1}{c}{ Casi Siempre } & \multicolumn{1}{c}{ Siempre } \\
\hline I.2 Me comunico de alguna manera con Dios & $22,9 \%$ & $30,9 \%$ & $42,5 \%$ \\
\hline $\begin{array}{l}\text { 7.Cuando me arrepiento de mis pecados siento que } \\
\text { Dios me perdona }\end{array}$ & $15,6 \%$ & $23,8 \%$ & $56,4 \%$ \\
\hline 9.Cuando medito siento la presencia de Dios & $21,3 \%$ & $24,8 \%$ & $46,4 \%$ \\
\hline 24. Mi fe está integrada a mi vida & $16,0 \%$ & $29,5 \%$ & $49,1 \%$ \\
\hline Promedio & $19,0 \%$ & 27,3 & $48,6 \%$ \\
\hline
\end{tabular}

En la tabla 12 se observa que la vivencia de Fe en sus vidas cotidianas es de nivel importante lo cual se evidencia con el 75,9\% de logro promedio. Entre los indicadores destaca "cuando me arrepiento de mis pecados siento que Dios me perdona" (56,4\% siempre)

\section{Práctica}

Los resultados obtenidos en cuanto a práctica muestran lo siguiente:

\section{Tabla 13. PRÁCTICA}

\begin{tabular}{|l|c|c|c|}
\hline \multicolumn{1}{c}{ Ítems } & A Veces & \multicolumn{2}{c|}{ Casi Siempre Siempre } \\
\hline $\begin{array}{l}\text { I.3. Me doy tiempo para orar sin necesidad que } \\
\text { alguien me obligue }\end{array}$ & $31,2 \%$ & $26,2 \%$ & $35,0 \%$ \\
\hline 4. Rezo a Dios en compañía de otras personas & $49,3 \%$ & $14,4 \%$ & $12,6 \%$ \\
\hline
\end{tabular}




\begin{tabular}{|l|c|c|c|}
\hline 5. Cuando rezo, pido también por otras personas & $9,0 \%$ & $20,3 \%$ & $66,2 \%$ \\
\hline 6. Rezo no solo para pedir, sino para agradecer & $12,4 \%$ & $19,4 \%$ & $61,8 \%$ \\
\hline 11. Me gusta leer la palabra de Dios( Biblia) & $53,3 \%$ & $15,6 \%$ & $10,8 \%$ \\
\hline $\begin{array}{l}\text { 19. Me doy espacio de silencio para ponerme en } \\
\text { contacto con mi yo interior }\end{array}$ & $52,3 \%$ & $29,6 \%$ & $32,5 \%$ \\
\hline Promedio & $34,6 \%$ & $20,9 \%$ & $36,5 \%$ \\
\hline
\end{tabular}

Logro $\quad \mathbf{5 7 , 4 \%}$

En la tabla 13 se ve que las estudiantes universitarias llevan a cabo una práctica moderada de la religión con el $57,4 \%$ de logro promedio.

\subsection{Dimensión psíquica (autoconciencia-autonomía)}

La dimensión psíquica de la espiritualidad fue evaluada por ítems que expresan autoconciencia y/o autonomía obteniéndose los resultados que se indican a continuación:

Tabla 14. Autoconciencia-Autonomía

\begin{tabular}{|l|c|c|c|}
\hline \multicolumn{1}{c}{ Ítems } & A Veces & \multicolumn{1}{c}{ Casi Siempre } & \multicolumn{1}{c}{ Siempre } \\
\hline $\begin{array}{l}\text { I.15 Disfruto compartir con otras personas que } \\
\text { creen lo mismo que Yo }\end{array}$ & $19,7 \%$ & $29,1 \%$ & $46,8 \%$ \\
\hline 18. Busco desarrollarme espiritualmente & $30,1 \%$ & $32,0 \%$ & $31,2 \%$ \\
\hline 22. Disfruto escuchando música que me da paz & $24,7 \%$ & $26,2 \%$ & $49,9 \%$ \\
\hline 25.Evito perder el tiempo en asuntos inútiles & $44,1 \%$ & $29,9 \%$ & $22,1 \%$ \\
\hline II.1Creo en mí y tomo mis propias decisiones & $8,6 \%$ & $35,0 \%$ & $55,9 \%$ \\
\hline $\begin{array}{l}\text { 2. Mis decisiones tienen como referencia mis valores } \\
\text { y principios }\end{array}$ & $4,5 \%$ & $25,8 \%$ & $69,1 \%$ \\
\hline $\begin{array}{l}\text { 3. Actúo bajo mis convicciones y normas asumidas } \\
\text { en mi vida }\end{array}$ & $7,4 \%$ & $47,0 \%$ & $63,4 \%$ \\
\hline 4. Suelo expresar mis sentimientos y emociones & $23,4 \%$ & $32,8 \%$ & $42,0 \%$ \\
\hline 6. Me esfuerzo por crecer en libertad & $7,3 \%$ & $24,7 \%$ & $68,4 \%$ \\
\hline $\begin{array}{l}\text { 7. Me hago responsable de las consecuencias de } \\
\text { mis acciones }\end{array}$ & $5,3 \%$ & $25,8 \%$ & $68,6 \%$ \\
\hline $\begin{array}{l}\text { 10. Me considero una persona empeñosa y } \\
\text { persistente }\end{array}$ & $11,0 \%$ & $35,4 \%$ & $52,8 \%$ \\
\hline 12. Me siento contenta conmigo misma & $9,6 \%$ & $29,7 \%$ & $59,4 \%$ \\
\hline 13. Valoro mis cualidades & $8,5 \%$ & $24,8 \%$ & $65,9 \%$ \\
\hline 14. Reconozco mis limitaciones & $9,2 \%$ & $32,6 \%$ & $57,1 \%$ \\
\hline 15. Encuentro sentido en lo que hago & $10,0 \%$ & $32,1 \%$ & $57,1 \%$ \\
\hline $\begin{array}{l}\text { 16. Estoy desarrollando una manera propia de ver } \\
\text { la vida }\end{array}$ & $9,1 \%$ & $31,0 \%$ & $58,1 \%$ \\
\hline 19. Intento coherencia entre lo que digo y hago & $7,4 \%$ & $42,4 \%$ & $49,4 \%$ \\
\hline $\begin{array}{l}\text { 21. Veo el futuro como una manera propia de ver la } \\
\text { vida }\end{array}$ & $5,3 \%$ & $28,5 \%$ & $65,4 \%$ \\
\hline 22. Me esfuerzo por ser cada día mejor persona & $4,5 \%$ & $25,6 \%$ & $69,4 \%$ \\
\hline
\end{tabular}




\begin{tabular}{|l|c|c|c|}
\hline 23. Aprendo de mis errores & $8,5 \%$ & $32,4 \%$ & $58,7 \%$ \\
\hline 25. Evito sustancias y prácticas que dañan mi salud & $15,1 \%$ & $23,1 \%$ & $59,7 \%$ \\
\hline III.9. Sé escuchar a los demás & $5,5 \%$ & $29,2 \%$ & $64,7 \%$ \\
\hline 10. Soy agradecida con las personas & $4,4 \%$ & $18,2 \%$ & $76,5 \%$ \\
\hline $\begin{array}{l}\text { 11. Necesito tener un vínculo emocional fuerte con } \\
\text { las personas }\end{array}$ & $31,4 \%$ & $35,4 \%$ & $28,5 \%$ \\
\hline 12. Me alegro con los éxitos de mis compañeras/os & $5,3 \%$ & $26,6 \%$ & $67,5 \%$ \\
\hline $\begin{array}{l}\text { 13. Me indignan las injusticias especialmente con } \\
\text { los más débiles }\end{array}$ & $2,6 \%$ & $17,3 \%$ & $79,1 \%$ \\
\hline 15. Me desagrada el trabajo en grupo & $33,4 \%$ & $7,5 \%$ & $6,2 \%$ \\
\hline 16. Me gusta ser una persona autosuficiente & $15,2 \%$ & $30,1 \%$ & $50,7 \%$ \\
\hline 19. Me gusta servir a la gente & $17,2 \%$ & $32,6 \%$ & $48,6 \%$ \\
\hline 20. Cuido no excluir a las personas & $9,6 \%$ & $32,4 \%$ & $56,7 \%$ \\
\hline 22. Intento ser justa en mis decisiones & $7,3 \%$ & $36,5 \%$ & $55,2 \%$ \\
\hline 23. Soy sincera con mis compañeras & $7,0 \%$ & $32,1 \%$ & $59,8 \%$ \\
\hline 24. Soy exigente con los demás & $25,2 \%$ & $33,2 \%$ & $39,4 \%$ \\
\hline 25.Administro mi dinero en forma responsable & $29,7 \%$ & $33,9 \%$ & $30,9 \%$ \\
\hline Promedio & $15,1 \%$ & $29,7 \%$ & $55,5 \%$ \\
\hline
\end{tabular}

$\begin{array}{lll}\text { Logro } & \mathbf{8 5 , 2} \%\end{array}$

En la tabla 14 se muestra que las estudiantes en lo referente a su autoconciencia y autonomía tienen un logro promedio importante de $85,2 \%$ lo que significa un muy alto nivel de formación personal, siendo el indicador "me indignan las injusticias especialmente con los más débiles" el que más destaca (79,1\% siempre), seguido por "soy agradecida con las personas" (76,5\% siempre), "me esfuerzo por ser cada día mejor persona" (69,4\% siempre), "mis decisiones tienen como referencia mis valores y principios" (69,1\% siempre), "me hago responsable de las consecuencias de mis acciones" (68,6\% siempre) y "me esfuerzo por crecer en libertad" (68,4\% siempre).

\subsection{Dimensión relacional (fenomenológica)}

La dimensión relacional evaluada por el instrumento muestra los resultados que aparecen a continuación:

Tabla 15. Relaciones

\begin{tabular}{|l|c|c|c|}
\hline \multicolumn{1}{c}{ Ítems } & A Veces & \multicolumn{1}{c}{ Casi Siempre } & Siempre \\
\hline $\begin{array}{l}\text { I.12. Mis compañeras se dan cuenta que soy } \\
\text { creyente }\end{array}$ & $35,9 \%$ & $22,5 \%$ & $18,5 \%$ \\
\hline 13. Perdono las ofensas que me hacen & $23,8 \%$ & $43,1 \%$ & $30,3 \%$ \\
\hline $\begin{array}{l}\text { 14. Mis compañeras reconocen que algo superior } \\
\text { conduce mi vida }\end{array}$ & $34,9 \%$ & $22,3 \%$ & $15,9 \%$ \\
\hline 16. Realizo acciones en bien de los demás & $22,2 \%$ & $40,6 \%$ & $35,9 \%$ \\
\hline 17. Me involucro en acciones para cuidar el medio & $30,9 \%$ & $29,9 \%$ & $23,1 \%$ \\
\hline 20. Trato de vivir en armonía con la naturaleza & $17,4 \%$ & $37,8 \%$ & $42,4 \%$ \\
\hline 21. Trato de apoyar a los más necesitados & $24,0 \%$ & $38,8 \%$ & $35,5 \%$ \\
\hline II.5. Respeto la dignidad de las personas & $3,2 \%$ & $18,9 \%$ & $77,5 \%$ \\
\hline
\end{tabular}




\begin{tabular}{|l|c|c|c|}
\hline 8. Me duele el sufrimiento que hay en el mundo & $12,4 \%$ & $24,0 \%$ & $62,7 \%$ \\
\hline 9. Protesto ante la corrupción & $22,6 \%$ & $28,5 \%$ & $42,5 \%$ \\
\hline 11.Valoro la vida humana desde su concepción & $6,9 \%$ & $16,0 \%$ & $76,0 \%$ \\
\hline 17. Busco proteger la vida & $8,9 \%$ & $22,2 \%$ & $67,9 \%$ \\
\hline $\begin{array}{l}\text { 18. En mi relación con las personas soy honesta y } \\
\text { responsable }\end{array}$ & $5,5 \%$ & $33,3 \%$ & $60,8 \%$ \\
\hline 20. me informo sobre los problemas del mundo & $32,5 \%$ & $40,0 \%$ & $24,4 \%$ \\
\hline $\begin{array}{l}\text { 24. Reconozco posibilidades en las situaciones } \\
\text { difíciles }\end{array}$ & $13,2 \%$ & $37,6 \%$ & $47,8 \%$ \\
\hline III.1. Respeto a personas de diferentes creencias & $2,4 \%$ & $10,6 \%$ & $86,8 \%$ \\
\hline 2. Respeto las opiniones de los otros & $2,5 \%$ & $18,6 \%$ & $78,6 \%$ \\
\hline $\begin{array}{l}\text { 3. Comparto información profesional con mis } \\
\text { compañeras/os de carrera }\end{array}$ & $11,6 \%$ & $31,6 \%$ & $55,9 \%$ \\
\hline 4. Apoyo la iniciativa de los otros & $8,2 \%$ & $31,7 \%$ & $59,2 \%$ \\
\hline 5. Fomento las buenas relaciones & $4,9 \%$ & $27,9 \%$ & $66,7 \%$ \\
\hline 6. Trabajo en colaboración con los demás & $7,0 \%$ & $30,6 \%$ & $61,6 \%$ \\
\hline 7. Busco soluciones a los conflictos & $7,0 \%$ & $36,3 \%$ & $55,7 \%$ \\
\hline 8. Me gusta ayudar a las personas en dificultad & $7,4 \%$ & $26,9 \%$ & $65,0 \%$ \\
\hline 14. Perdono las ofensas recibidas & $21,3 \%$ & $40,6 \%$ & $35,4 \%$ \\
\hline 17. Busco fortalecer relaciones con otras personas & $11,2 \%$ & $34,7 \%$ & $52,3 \%$ \\
\hline $\begin{array}{l}\text { 18. Realizo acciones solidarias con personas } \\
\text { necesitadas }\end{array}$ & $22,5 \%$ & $31,8 \%$ & $43,5 \%$ \\
\hline 21. Digo la verdad sin herir & $25,4 \%$ & $41,5 \%$ & $30,5 \%$ \\
\hline Promedio & $15,8 \%$ & $30,3 \%$ & $50,1 \%$ \\
\hline
\end{tabular}

En la tabla 15 la muestra en estudio evidencia que ellas establecen unas buenas relaciones con el $80,4 \%$ de nivel promedio, siendo el indicador "respeto a personas de diferentes creencias" el que más destaca ( $86,8 \%$ siempre), seguido de "respeto las opiniones de los otros" (78,6\% siempre) y "respeto la dignidad de las personas" (77,5\% siempre).

\section{Sobre lo que piensan las estudiantes universitarias}

\subsection{Sobre la Sociedad Peruana}

De 757 opinantes se ha tomado una muestra de 280 que representa al 37\%. De esta muestra el $87 \%$ simplemente da su opinión; el $13 \%$ restante emite opinión y al mismo tiempo señala algún curso de acción o propuesta de solución.

Cabe destacar que la opinión de una estudiante contiene una o más representaciones sobre la sociedad peruana. El examen de contenido arroja la siguiente frecuencia por tipos de representaciones: 


\section{Tabla 16 Tipos de representaciones sobre la sociedad peruana}

\begin{tabular}{ccc}
\hline Representaciones & Frecuencia & $\%$ \\
\hline Sociológicas & 118 & 27 \\
Psicológicas & 92 & 21 \\
Éticas & 92 & 21 \\
Axiológicas & 64 & 15 \\
Históricas & 32 & 7 \\
Otras & 39 & 9 \\
\hline Total & 437 & 100 \\
\hline
\end{tabular}

La tabla 16 muestra que las estudiantes universitarias inciden más en representaciones psicosociales (48\%), seguido de representaciones de carácter ético-valorativo (36\%)

Los problemas consensuales, construidos como representaciones colectivas en las que se reconocen inmersas las estudiantes universitarias, son de orden psicosocial y axioéticos, destacando:

\section{La inseguridad ciudadana y \\ la violencia. Así dicen: "hay} mucha delincuencia, asesinatos"; "actualmente estamos en un tiempo en el cual en la sociedad existe mucha delincuencia e inseguridad ciudadana. Es un gran problema"; "cada vez está peor, hay más delincuencia"; "creo que en los últimos años la sociedad se ha tornado más peligrosa...es más común oír sobre asaltos, asesinatos, violaciones"; en nuestra sociedad hay mucha delincuencia, en la cual uno no está seguro ni en su propia casa; "es una porquería, tanto delincuente que hay por allí, violador y más"

La discriminación: "hay desde inseguridad, discriminación racial y sexual"; cada vez hay más discriminación...por alguna razón los medios de comunicación hacen influenciar"; "es una sociedad en donde la discriminación es pan de cada día"; "la discriminación se mantiene latente"; "discriminación en cada esquina"

Las actitudes prevalentes de desconfianza, individualismo, y trivialidad: "somos muy desconfiados el uno del otro"; "nadie cree ya en nadie"; "cada persona baila con su pañuelo"; "el que es vivo gana"; "cada uno camina con su propio pié"; "las personas se interesan más por temas triviales"; "la juventud de ahora suele ocuparse por temas poco importantes"

La corrupción: "cada vez se vuelve peor la situación del país, solo se ve corrupción"; "es una sociedad que está llena de mucha corrupción"; "demasiada corrupción, incluso con las personas que tienen un alto cargo"; "nuestra sociedad está cada día más metida en la corrupción".

Las propuestas frente a las características señaladas sobre la sociedad peruana inciden también en aspectos psicosociales y en dirección axiológica, que van desde exigir leyes más drásticas hasta inculcar valores a nuevas generaciones, pasando por las motivaciones personales de cambio y la práctica de valores como la solidaridad, el apoyo mutuo, la honestidad y la responsabilidad.

El pensamiento sobre la sociedad peruana que construyen las estudiantes universitarias corresponde a una sociedad insegura, violenta, discriminatoria y corrupta.

\subsection{Sobre la Familia}

En lo referente a los resultados de la encuesta sobre la percepción de "Familia" que tienen las estudiantes universitarias de UNIFÉ, se obtuvo diversas respuestas según su vivencia y su sentir personal, evidenciando que esta 
institución sigue siendo un pilar esencial de su formación pues la valoran y la consideran como el núcleo más importante, como el lugar donde se cimenta el proceso de socialización, como un lugar de apoyo incondicional, en donde se sienten seguras y queridas y en donde se encuentra también amor, paz, confianza, y también severidad.

En palabras de las estudiantes "allí se forman las buenas personas"; "es el núcleo de la sociedad",; "es donde se enseñan valores"; "es donde acudo en los momentos difíciles"; "es el sentido de mi vida"; "me siento agradecida por mi familia".

Estoesenlopositivoperotambién hayopiniones encontradas: "estamos acomplejados por creer que familia es papá, mamá e hijos, cuando hay familias formadas por abuelos tíos etc, lo que importa es que haya amor significativo entre un grupo de personas bajo un mismo techo"; "la familia es uno mismo porque al final te quedas sola como viniste al mundo"; "la familia de hoy está en proceso de extinción por los divorcios múltiples y las infidelidades y además promovido por los medios de comunicación en las novelas"; "apoyo el otro tipo de familia entre homosexuales"; "es una institución no protegida"; "el padre saca la vuelta"; " no tengo una familia, mi familia es mi madre y mis amigas".

\subsection{Sobre la Espiritualidad}

Sobre una muestra de 263 estudiantes, 6 universitarias responden no saber qué es la espiritualidad, 2 se declaran no creyentes y algunas otras lamentan que la juventud descuide la espiritualidad. Se ha sistematizado las respuestas en dos aspectos. En el primero se presenta lo que piensan las universitarias sobre la espiritualidad y en el segundo se muestra la valoración que hacen sobre la espiritualidad.

La concepción de espiritualidad que tienen las universitarias de UNIFÉ expresa cómo se comprenden a sí mismas como personas. La espiritualidad constituye la esencia de la persona; por lo mismo es irrepetible; es la explicación más profunda que la persona puede encontrar de sí misma es interioridad y ser persona supone interioridad, ser espiritual. Según algunas "no necesariamente tiene que ser algo religioso"

Al ser esencia de la persona, no es sólo una vivencia cognitiva, intimista, limitada al yo, sino que estructura a la persona en sus diferentes dimensiones, "refleja lo que la persona es, lo que la define". Es vida y una determinada forma de vida testimonial, por lo mismo la espiritualidad es relación. "Vivir una espiritualidad o forma de vida es una guía para fortalecernos como personas, para saber quiénes somos, hacia dónde vamos y compartirla con el testimonio que es una constante diaria"

Es una manera de relacionarse la persona consigo misma, le permite conocer lo que es, quién es, por qué existe, qué siente. "Es conocer nuestro interior y saber qué es lo que somos y sentimos". Se constituye pues en espacio de reflexión sobre los propios actos: "implica el espacio que tiene una persona para reflexionar sobre sus actos analizar y conducir su vida a un estado de goce".

Asimismo, la espiritualidad lleva a la persona más allá del yo, del sujeto en su realidad de ser autónomo, lo abre a la conciencia de su trascendencia en el mundo, la cual identifica con la búsqueda de vida plena, de felicidad: "Nos ayuda a buscar trascender, es una fuerza interna independientemente de la religión que profesamos, que nos impulsa a actuar por el bien supremo y sobre todo es energía movilizadora". "En las personas no creyentes la espiritualidad la definen como hacer el bien a los demás, respetando a la sociedad"

En la mayoría de las respuestas la espiritualidad se relaciona con la fe en Dios: "es la búsqueda de Dios que clama con fuerza en nuestro interior porque fuimos creados por El". "Es lo más profundo de nosotras, que nos llena el corazón, nos hace sentir la felicidad, es un anhelo de Dios que tiene el hombre".

La espiritualidad es praxis, como energía y fuerza interna, impulsa a dar lo mejor, a creer y actuar por el Bien Supremo. Implica las actitudes, decisiones y acciones; humaniza a 
la persona: "Es la imagen y personalidad de la persona, su máxima intimidad, que sólo ella conoce, es el lado sensible, humano y real que existe en cada uno"

Según las jóvenes, la espiritualidad crece con la práctica, se cultiva, se alimenta con las buenas acciones, la oración y la palabra de Dios, y se va formando desde pequeñas en base a principios. "Es trascender en virtud, convertirte en uno mejor, conocer acerca de uno mismo y entrar en contacto con el otro". "La espiritualidad se siente en el acto compasivo, es sentimiento de amor y de fe entre otros."

Considerando la valoración que hacen las universitarias de la espiritualidad se destaca en primer lugar que el conjunto de las jóvenes tienen una concepción muy positiva de la espiritualidad; la consideran esencial para su desarrollo y para ser mejores personas, porque lleva a ser humanos. Vivir la espiritualidad humaniza a la persona, "ayuda a no perder de vista las metas y los ideales de la vida". Sus expresiones revelan que la espiritualidad es en ellas una vivencia: "genera paz, y sentirse bien consigo misma, da equilibrio interior $y$ armonía"; "ayuda de forma gratificante, da apoyo para seguir adelante, es una base para ser buena y honesta. Lleva a la superación y trascendencia, ayuda a luchar contra el sin sentido de la vida y la injusticia y permite apreciar la belleza espiritual. Una vida sin espiritualidad no es vida."

En segundo lugar reconocen que la espiritualidad es tan necesaria para la vida personal como para la convivencia en la sociedad y hace falta vivirla con prioridad, porque hay hambre de Dios: "Sin ella hay vacío, no hay límites ni esperanza, ni amor ni felicidad. "Es el fundamento, cimiento básico en la vida".

\subsection{Ser joven hoy}

De acuerdo a la encuesta aplicada en la UNIFÉ, las estudiantes universitarias tienen una valoración positiva de la etapa de la juventud. Su visión es de posibilidades y retos que pueden cumplir y superar. Consideran que el esfuerzo que deben desplegar se justifica por los logros que alcanzarán, así el esfuerzo fructifica en la búsqueda de concreción de logro de objetivos y expectativas.

Los jóvenes consideran la juventud como el momento en el cual pueden desarrollarse y capacitarse para llegar a ser profesionales y puedan realizarse dentro de la actividad laboral. Aunque son conscientes del mundo competitivo del trabajo, de la demanda de una preparación continua y de la necesidad de competentes en otros saberes como informática $e$ idiomas. Un punto que produce inquietud en los jóvenes es su posición frente al mundo laboral a partir de las posibilidades que se les ofrece y de las demandas que se les exige.

Si bien es cierto que hay un espíritu de apertura y jovialidad, también se percibe cierta aprehensión por los problemas que no ha resuelto la sociedad y por su incongruencia entre los valores que propicia y los hechos concretos. También suscita inquietudes su libertad, aunque en general consideran que todo es factible de ser asumido con una formación en valores y con el apoyo de personas que les ayuden a salir adelante.

\subsection{La religión}

De acuerdo a la encuesta aplicada a las estudiantes de la UNIFÉ sobre la percepción de la religión las respuestas apuntan hacia un consenso sobre su trascendencia y sobre la necesidad de una comunicación con Dios en el diario vivir. Consideran que la creencia se empalma con la formación espiritual con el fin de conocer la fe y alcanzar un mayor desarrollo espiritual. Desarrollo que no queda en ellas mismas, sino que se traduce en obras que buscan el apoyo al prójimo. De esa manera, se concibe una fe dinámica, en crecimiento continuo personal, pero con una mirada abierta a los demás.

También consideran que dentro de un mundo en el que las relaciones humanas se mediatizan por la tecnología, sienten que la religión las acompaña y ayuda a no sentirse solas. Además, les ayuda a vivir en armonía y 
a desarrollarse en todos los planos tratando de ser mejores personas.

Las jóvenes consideran que la religión les permite ver la realidad de una manera particular, es decir, valorar lo bueno que existe en la vida y les ayuda a superar lo negativo. Además, un punto que consideran importante es que la religión pone límites, sobre todo por la permeabilidad de la sociedad. Todo ello les ayuda de encontrar cauces que orienten su vida dado que brinda valores que orientan la vida y contribuyen a generar un perfil positivo de su persona. De esa manera pueden tener paz interior y tranquilidad.

Un punto de coincidencia en la opinión de las jóvenes es que la religión debe ser elegida libremente con respeto y tolerancia a la diversidad de creencias.

Desde otra vertiente, dentro de un plano de libertad, se manifiesta que cada uno decide si cree o no. Esto se debe a que algunas estudiantes manifiestan ser agnósticas, pero respetuosas de las creencias de los demás.

\section{CAPÍTULO V}

\section{DISCUSIÓN}

Al abordar la presente investigación planteamos conocer la existencia y características del soporte espiritual de las jóvenes universitarias al afrontar los retos del mundo actual que ponen en cuestión su propia razón de ser; para lo cual diseñamos un perfil sobre la espiritualidad como manifestación de sí mismas en las dimensiones de su fe, en el desarrollo de su personalidad $y$ en sus relaciones interpersonales, las cuales son confrontadas $e$ integradas con lo que piensan en relación a diferentes contextos de su entorno, como son la sociedad, la familia, la espiritualidad, la juventud y la religión.

La estudiante universitaria de la UNIFÉ como persona creyente, que tiene una fe $y$ la practica, vale decir, su espiritualidad en sentido ontológico, como la manera de ser y de vivir, abierta hacia Dios, según lo expresado por Bazán (2008) manifiesta en un porcentaje significativo sus creencias y vivencias y en menor proporción sus prácticas de fe. El 92\% reconoce tener una religión, siendo en su mayoría católicas. El estudio muestra una gran valoración de las creencias. Como esta percepción se va formando desde la niñez y se va convirtiendo en vivencia y en práctica más o menos consciente, se puede afirmar que tienen una base religiosa fuerte. No solo queda a nivel de la creencia, sino de fe. Sus expresiones en general son explícitamente cristianas. Hacen referencia al Dios de Jesucristo. Asimismo, expresan comunicarse con Dios y orar; tienen conciencia de caminar acompañadas por Dios, no están solas, que su fe se hace vida $y$, por tanto, su espiritualidad constituye una manera de ser, de insertarse en la realidad.

La experiencia de Dios en la vida la describe Nolan (2007) como una transformación de las personas que se traduce en felicidad. Esta felicidad en definitiva es un Dios que es amor, que cuida a la persona. Por consiguiente, la espiritualidad es relación permanente, confiada, amical con Dios y con los demás; es relación de amor, se pone en el lugar del otro y lo ayuda. Es así mismo, relación con el medio. Es algo de Dios que lleva a la confianza, a vivir las creencias con libertad y pone a la persona en un punto de equilibrio.

Una característica específica de esta espiritualidad se descubre al examinar los ítems sobre las creencias y vivencias de la fe. En efecto, llama la atención el sentido de Dios misericordioso y compasivo $(81 \%)$ y la vivencia del perdón (56\%). Mientras que en los ítems de práctica destaca la oración por otras personas $(60 \%)$.

Comparando los ítems de la espiritualidad en su dimensión del ser es notorio que el logro de práctica $(57 \%)$ religiosa (ir a misa, leer la palabra de Dios) es bastante menor que el de creencias (81\%) y el de vivencias de la fe $(76 \%)$. Esto podría explicarse por la dedicación y exigencias de la labor académica de las estudiantes universitarias que limita sus posibilidades para orar por ejemplo en compañía de otras personas, para leer la palabra de Dios, para encontrarse en silencio consigo misma. 
Por otro lado, al examinar los resultados desde la dimensión psíquica de la espiritualidad se observa que las estudiantes universitarias muestran un perfil de su personalidad con características definidas: su sensibilidad frente a las injusticias, especialmente con los más débiles (79\% siempre); su disposición de gratitud con respecto a las personas $(77 \%)$ y, la toma decisiones teniendo como referencia los propios valores y principios (69\%), acompañado del esfuerzo por ser cada día mejor persona (69\%), el hacerse responsable de las consecuencias de las propias acciones $(68 \%)$ y el esfuerzo por crecer en libertad (68\%).

Si bien los porcentajes de logro indican que hay que trabajar más en estos atributos de la personalidad de las estudiantes universitarias, sin embargo es pertinente ponerlos en relieve porque responden a lo esperado por la formación axiológica en la Universidad; porque es coherente con la percepción de sí mismas y de la sociedad peruana.

Las estudiantes, no perciben los problemas estructurales de la sociedad peruana, tanto que no elaboran imágenes de conflictos socioeconómicos entre las diferentes clases sociales. Así se entiende que el universo consensual que constituye el rasgo distintivo de las representaciones que tienen sobre la sociedad peruana y que tiñe de significados su preparación profesional actual gira en torno a problemas coyunturales que son, como afirma una encuestada, "el pan de cada día", los mismos que son exacerbados por los medios de comunicación y en las redes sociales. Es por ello que en la percepción que tienen sobre la sociedad peruana actual destacan problemas que los hemos denominado psicosociales y axioéticos, como son la violencia, la discriminación y la corrupción, entre otros (ver Anexo no 3 )

Finalmente, siendo que la mayoría, por no decir todas las estudiantes, dependen de su entorno familiar para mantenerse y seguir estudios universitarios, lo esperado es una actitud abierta al agradecimiento, a la gratitud.
Otros rasgos de la personalidad que se pueden observar en las estudiantes encuestadas son la expresión de sentimientos y emociones, intentan ser coherentes, tener vínculo emocional fuerte con las personas, ser exigente consigo mismas. Podemos afirmar, entonces, que la espiritualidad configura la personalidad.

Finalmente los resultados de los ítems referidos a la espiritualidad expresada en las vivencias de las relaciones interpersonales muestran de manera muy clara la intencionalidad manifiesta en el valor del respeto como exigencia esencial de la convivencia humana. Los mayores logros se centran en el respeto a personas de diferentes creencias (87\%), respeto a las opiniones de los otros $(79 \%)$ y el respeto a la dignidad de las personas (78\%).

Los jóvenes forman parte de un sector dinámico dentro de la sociedad, de ahí que se les adscriba el deseo de concretar metas con fe en el futuro.

La encuesta aplicada a las estudiantes sobre lo que significa "El ser joven hoy" implica un distanciamiento de su realidad, dado que se implican el sujeto y el objeto del análisis. Esa mirada personal resulta fundamental $e$ incide en una riqueza y diversidad de respuestas que dependen de la experiencia personal, de la capacidad para manifestar la aprehensión del perfil personal, de las motivaciones subjetivas y de las coordenadas de su contexto.

La auto percepción de las jóvenes demuestra sus proyecciones personales que operan en su vida y orientan los pasos que debe dar para concretarlos; por otra, de la conciencia de la presión de la sociedad que demanda respuestas para insertarse en la vida nacional y responder en forma autónoma. Todo ello implica responsabilidad y proyección al futuro. Todo ello exige oportunidades para poder expresarse y ser escuchado también con respeto.

Para las estudiantes la espiritualidad, por la propia dinámica de la vida universitaria, las pone en conexión con los problemas del hombre actual, de la sociedad peruana y del entorno físico-natural y social. 
Creemos que una espiritualidad centrada en la relación con Dios y que ayude a la persona a ser cada vez más humana y cada vez más humanizadora en sus relaciones con los otros $y$ con la creación, habrá encontrado un sentido a su vida.

\section{CONCLUSIONES Y RECOMENDACIONES}

A continuación se presentan las conclusiones y recomendaciones que se derivan del presente estudio:

\section{Conclusiones}

1.1 La espiritualidad se expresa como vivencia y práctica de fe, que se cultiva en el desarrollo de la personalidad $y$ se testimonia en las relaciones interpersonales.

1.2 Las estudiantes universitarias atribuyen una gran valoración a las creencias, especialmente asociadas a la imagen de un Dios misericordioso y compasivo. Sin embargo, los niveles de logro relacionados a las vivencias y práctica de la fe son moderadas.

1.3 La dimensión psíquica de la espiritualidad de las estudiantes universitarias es la que alcanza el más alto porcentaje de logro en comparación a la dimensión ontológica y relacional.

1.4 Las estudiantes universitarias muestran un perfil definido de crecimiento y maduración de su personalidad lo cual se manifiesta en su posición frente a situaciones injustas, su predisposición para la espiritualidad agradecer y asumir las consecuencias de las propias acciones que constituyen su propia fortaleza.

1.5 La dimensión relacional de las estudiantes demuestraunaimportante valoración respecto a las diferentes creencias, a las opiniones de otros y a la dignidad de las personas que se manifiesta en perdonar las ofensas, realizar acciones en bien de los demás y respetar la dignidad de las personas.

1.6 La estudiante universitaria durante su estancia en la UNIFÉ tiene oportunidades para discernir $y$ profundizar en la valoración de sus creencias, de su fe y prácticas; de una u otra forma la dinámica de los estudios contribuye a tener conciencia de los alcances del autodominio y la autodeterminación en el desarrollo y maduración de su personalidad $y$, asimismo, ensaya y perfila su vocación profesional de servicio para los más necesitados.

1.7 El perfil que muestran las estudiantes se adecúa a la misión y visión de la UNIFÉ en tanto se les procura una sólida capacitación científica $y$, de modo particular, una educación humanística, ética, de calidad, que se traduzca en profesionales cabales con vocación de servicio para lograr una sociedad más justa, solidaria e incluyente.

\section{Recomendaciones}

2.1 Se plantea diseñar metodologías $y$ organizar talleres y actividades diversas para sustentar, reforzar $y$ canalizar oportunidades y medios para vivencia de la fe cristiana y su expresión en las prácticas de fe, especialmente relacionadas con la eucaristía, lectura de la palabra y la oración.

2.2 Se propone profundizar la espiritualidad de las universitarias que se expresa como vivencia $y$ práctica de fe, que desarrolla la personalidad y fortalece la calidad de las relaciones interpersonales. Lo cual es una tarea importante dentro del marco de la formación integral que la Universidad Femenina del Sagrado Corazón se propone como Misión. 


\section{REFERENCIAS}

AQUINO, T. DE (1958-60). Suma Teológica. Madrid: Católica.

ARIAS, W; MASÍAS, M.A; MUÑOZ, E; ARPASI, M (2013) Espiritualidad en el ambiente laboral y su relación con la felicidad del trabajador Revista de Investigación 4(9-33). Arequipa, Universidad Católica San Pab

BAZÁN GAYOSO, Elizabeth (2008) Desafiados a la esperanza desde la espiritualidad que identifica a nuestra institución. En: PHAINOMENON (ISSN 1819-1983) Volumen 7 nº 8. Enero-Diciembre 2008 Revista del Departamento de Filosofía y Teología. Facultad de Psicología y Humanidades. Lima, Universidad Femenina del Sagrado Corazón.

CASTILLO, José M. (2008) Espiritualidad para Insatisfechos. Madrid, Trotta

CAZAU, P (2006) Introducción a la investigación en ciencias sociales. Modulo 404REDPSICOLOGÍA ONLINE - WWW.GALEON.COM/PCAZAU . Buenos Aires, Argentina.

FEDERACIÓN DE ESTUDIANTES EVANGÉLICOS DE EIUROPA-IFES (2013) Universitarios europeos: más espiritualidad relativista y menos religión. WWW.protestantedigital.com

FIORES, Stefano de; GOFFI, Tulio (1989) Nuevo diccionario de Espiritualidad. Madrid, Paulinas.

GALILEA, Segundo (1989) El camino de la espiritualidad. Santiago de Chile, Paulinas.

GARRIDO, Javier (1988) Una espiritualidad para hoy. Madrid, Paulinas.

INSTITUTO NACIONAL DE ESTADÍSTICA E INFORMÁTICA - INEI (2014) Compendio Estadístico Perú 2014. Lima, INEI T.I

JAMES, Anthony (2010) Preliminary Finding on qualitative exploration of children and youth's conceptualization spirituality. WWW.tendencias21.net Universidad Pontificia Comillas-Madrid. Cátedra de Ciencia, Tecnología y Religión

JODELET, Denise (1989) Representations Sociales: un domaine en expansión. En: Les Representations Sociales. Paris, PUF

LOBATO, Abelardo (1997) Dignidad y aventura humana. Madrid, EDIBESA

LUCAS LUCAS, Ramón (1999) El hombre espíritu encarnado. Compendio de Filosofía del Hombre. $2^{a}$ edic. Salamanca, Sígueme.

MORALES ARROYO, Sandra (2014) Relación entre la espiritualidad, el bienestar físico y el bienestar psicológico de las estudiantes universitarias. Revista Griot (ISSN 1949-4742) Volumen 7, No 1, Nov. 2014. Puerto Rico. Pontificia Universidad Católica.). Recuperado de http://revistagriot. uprrp.edu/archivos/Rvista_Griot_Vol_7_No_1_2014.pdf

NOLAN, Albert (2008) Jesús hoy: una espiritualidad de libertad radical. Barcelona, Sal Terrae SPINCK, Mary Jane (1993) Qualitative Research of Social Representations. En: Papers on Social Representations. Vol.2 (1) 
TURPO CHAPARRO, Josué E. (2011) Espiritualidad y rendimiento académico: un estudio comparativo entre alumnos internos alumnos externos de la Universidad Peruana Unión. http:// www.academia.edu/2387827/H\%C3\%A1bitos_de_estudio_espiritualidad_y_rendimiento_ acad\%C3\%A9mico_un_estudio_comparativo_entre_alumnos_internos_y_alumnos_externos de_la_Universidad_Peruana_Uni\% $\overline{\%} 3 \%$ B3n

VÁSQUEZ BOREAU J.L (1997) Espiritualidad. En: Moreno Villa, Mariano, Dir. Diccionario de Pensamiento Contemporáneo Madrid, San Pablo 


\section{ANEXO No 1 \\ CUESTIONARIO SOBRE ESPIRITUALIDAD}

Agradecemos su colaboración para responder este cuestionario que permitirá conocer la espiritualidad de las jóvenes. La información será confidencial.

INSTRUCCIONES: Por favor, sírvase marcar con un aspa $(\mathrm{x})$ en el recuadro que corresponde a su respuesta:

I. Programa Académico en el que se encuentra matriculada:

\begin{tabular}{|c|c|c|}
\hline $\begin{array}{l}\text { Administración de } \\
\text { Negocios } \\
\text { Internacionales }\end{array}$ & Arquitectura & $\begin{array}{l}\text { Ciencias de la } \\
\text { Comunicación }\end{array}$ \\
\hline Contabilidad y Finanzas & Derecho & $\begin{array}{l}\text { Educación } \\
\text { (Especifique) }\end{array}$ \\
\hline Nutrición y Dietética & Psicología & $\begin{array}{l}\text { Traducción e } \\
\text { Interpretación }\end{array}$ \\
\hline
\end{tabular}

2. Ciclo académico en el que se encuentra matriculada:

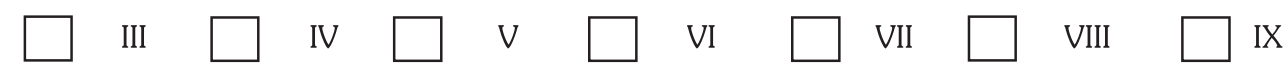

3. Edad año

4. Tipo de colegio en el cual concluyó su quinto grado/año de educación secundaria:

\begin{tabular}{|c|c|}
\hline Público & Privado (Particular / cooperativo u otro) \\
\hline Parroquial & Municipal \\
\hline
\end{tabular}

5. Estado civil:

\begin{tabular}{|c|c|c|}
\hline Soltera & Casada & Conviviente \\
\hline Separada & Divorciada & Viuda \\
\hline
\end{tabular}

6. Religión que profesa:

$\square$ Católica
$\square$ Anglicana
$\square$ Ninguna


7. Persona con quien vive:

\begin{tabular}{|c|c|c|c|}
\hline Madre & Padre & Ambos padres & Familiar \\
\hline Esposo & Pareja & Amigo(a) & Sola \\
\hline
\end{tabular}

8. Situación laboral:

9. Estudios superiores:

Únicamente en $\square$ También en otro centro
UNIFÉ

10. Financiamiento de estudios:

$\begin{array}{llll}\square & \text { Madre } & \text { Padre } & \text { Ambos padres } \\ \square \text { Esposo } & \text { Familiar } \\ & \text { Autofinanciamiento } & \text { Otros }\end{array}$

(Especifique)

11. Pertenencia a una organización y/o grupo social actualmente. (Puede marcar más de una categoría):

\begin{tabular}{|c|c|c|c|c|}
\hline Club social & Club deportivo & Grupo vecinal & Grupc & político \\
\hline $\begin{array}{l}\text { Grupo } \\
\text { parroquial }\end{array}$ & $\begin{array}{l}\text { Grupo religioso } \\
\text { organizado }\end{array}$ & $\begin{array}{l}\text { Grupo de } \\
\text { voluntariado }\end{array}$ & Otros & (Especifique) \\
\hline $\begin{array}{l}\text { Grupo } \\
\text { estudiantil } \\
\text { universitario }\end{array}$ & Ningún grupo & & & \\
\hline
\end{tabular}

\section{ESPIRITUALIDAD}

\begin{tabular}{|c|c|c|c|c|c|}
\hline $\mathrm{N}^{\circ}$ & Indicadores & A veces & $\begin{array}{l}\text { Casi } \\
\text { siempre }\end{array}$ & Siempre & Nunca \\
\hline 1. & Necesito de Dios, de alguien trascendente & & & & \\
\hline 2. & Me comunico de alguna manera con Dios & & & & \\
\hline 3. & Me doy tiempo para orar sin necesidad de que alguien me obligue & & & & \\
\hline 4. & Rezo a Dios en compañía de otras personas & & & & \\
\hline 5. & Cuando rezo, pido también por otras personas & & & & \\
\hline 6. & Rezo no sólo para pedir, sino para agradecer & & & & \\
\hline 7. & Cuando me arrepiento de mis pecados siento que Dios me perdona & & & & \\
\hline 8. & Dios, en quien creo, es misericordioso y compasivo & & & & \\
\hline 9. & Cuando medito siento la presencia de Dios & & & & \\
\hline
\end{tabular}




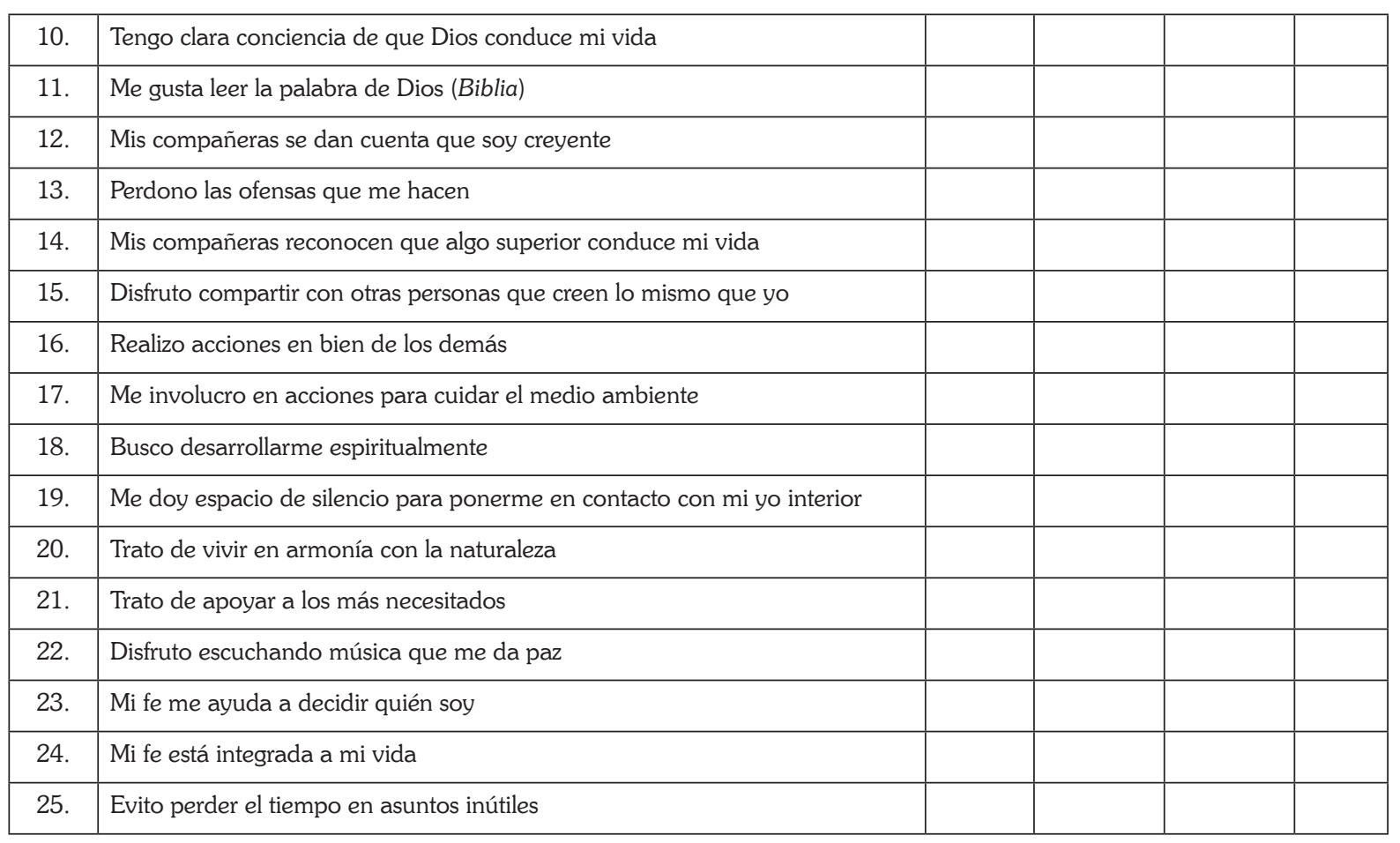

\section{ESPIRITUALIDAD}

\begin{tabular}{|c|c|c|c|c|c|}
\hline $\mathrm{N}^{\mathrm{O}}$ & Indicadores & A veces & $\begin{array}{c}\text { Casi } \\
\text { siempre }\end{array}$ & Siempre & Nunca \\
\hline 1. & Creo en mí y tomo mis propias decisiones & & & & \\
\hline 2. & Mis decisiones tienen como referencia mis valores y principios & & & & \\
\hline 3. & Actúo bajo mis convicciones y normas asumidas en mi vida & & & & \\
\hline 4. & Suelo expresar mis sentimientos y emociones & & & & \\
\hline 5. & Respeto la dignidad de las personas & & & & \\
\hline 6. & Me esfuerzo por crecer en libertad & & & & \\
\hline 7. & Me hago responsable de las consecuencias de mis acciones & & & & \\
\hline 8. & Me duele el sufrimiento que hay en el mundo & & & & \\
\hline 9. & Protesto ante la corrupción & & & & \\
\hline 10. & Me considero una persona empeñosa y persistente & & & & \\
\hline 11. & Valoro la vida humana desde su concepción & & & & \\
\hline 12. & Me siento contenta conmigo misma & & & & \\
\hline 13. & Valoro mis cualidades & & & & \\
\hline 14. & Reconozco mis limitaciones & & & & \\
\hline 15. & Encuentro sentido en lo que hago & & & & \\
\hline 16. & Estoy desarrollando una manera propia de ver la vida & & & & \\
\hline 17. & Busco proteger la vida & & & & \\
\hline 18. & En mi relación con las personas soy honesta y responsable & & & & \\
\hline 19. & Intento coherencia entre lo que digo y hago & & & & \\
\hline 20. & Me informo sobre los problemas del país & & & & \\
\hline 21. & Veo el futuro como una manera de realizarme y proyectar & & & & \\
\hline
\end{tabular}




\begin{tabular}{|c|l|l|l|l|l|}
\hline 22. & Me esfuerzo por ser cada día mejor persona & & & & \\
\hline 23. & Aprendo de mis errores y los corrijo sin que nadie me obligue & & & & \\
\hline 24. & Reconozco posibilidades en las situaciones difíciles & & & & \\
\hline 25. & Evito sustancias y prácticas que dañan mi salud & & & & \\
\hline
\end{tabular}

\section{ESPIRITUALIDAD}

\begin{tabular}{|c|c|c|c|c|c|}
\hline $\mathrm{N}^{\circ}$ & Indicadores & A veces & $\begin{array}{c}\text { Casi } \\
\text { siempre }\end{array}$ & Siempre & Nunca \\
\hline 1. & Respeto a personas de diferentes creencias & & & & \\
\hline 2. & Respeto las opiniones de los otros & & & & \\
\hline 3. & Comparto información profesional con mis compañeras/os de carrera & & & & \\
\hline 4. & Apoyo la iniciativa de otros & & & & \\
\hline 5. & Fomento las buenas relaciones & & & & \\
\hline 6. & Trabajo en colaboración con los demás & & & & \\
\hline 7. & Busco soluciones a los conflictos & & & & \\
\hline 8. & Me gusta ayudar a las personas en dificultad & & & & \\
\hline 9. & Sé escuchar a los demás & & & & \\
\hline 10. & Soy agradecida con las personas & & & & \\
\hline 11. & Necesito tener un vínculo emocional fuerte con las personas & & & & \\
\hline 12. & Me alegro con los éxitos de mis compañeras/os & & & & \\
\hline 13. & Me indignan las injusticias especialmente con los débiles & & & & \\
\hline 14. & Perdono las ofensas recibidas & & & & \\
\hline 15. & Me desagrada el trabajo en grupo & & & & \\
\hline 16. & Me gusta ser una persona autosuficiente & & & & \\
\hline 17. & Busco fortalecer relaciones con otras personas & & & & \\
\hline 18. & Realizo acciones solidarias con personas necesitadas & & & & \\
\hline 19. & Me gusta servir a la gente & & & & \\
\hline 20. & Cuido no excluir a las personas & & & & \\
\hline 21. & Digo la verdad sin herir & & & & \\
\hline 22. & Intento ser justa en mis decisiones & & & & \\
\hline 23. & Soy sincera con mis compañeras/os & & & & \\
\hline 24. & Soy exigente con los demás & & & & \\
\hline 25. & Administro mi dinero en forma responsable & & & & \\
\hline
\end{tabular}




\section{ESPIRITUALIDAD}

Diga lo que piensa, en un máximo de 4 líneas, sobre:

\section{La sociedad peruana}

\begin{tabular}{|l|}
\hline \\
\hline \\
\hline
\end{tabular}

2. La familia

\begin{tabular}{|l|}
\hline \\
\hline \\
\hline
\end{tabular}

3. La espiritualidad

\begin{tabular}{|l|}
\hline \\
\hline \\
\hline
\end{tabular}

4. Ser joven hoy

\begin{tabular}{|l|}
\hline \\
\hline \\
\hline
\end{tabular}

5. La religión

\begin{tabular}{|l|}
\hline \\
\hline \\
\hline
\end{tabular}

iiiGracias por su participación!!! 


\section{ANEXO No 2}

\section{LA SOCIEDAD PERUANA}

La sociedad peruana se caracteriza a grandes rasgos por su dinámica poblacional de rápido crecimiento especialmente desde la segunda mitad del siglo pasado. De seis (6) millones de habitantes en 1940 crece tres veces más en cuarenta años sobrepasando los 18 millones hacia 1988. La población proyectada al año de aplicación de cuestionario bordea los 31 millones. Esta transición demográfica ha significado un proceso de cambios en la sociedad peruana, siendo el más espectacular el proceso de urbanización: las tres cuartas partes de la población es urbana, estando en Lima, ciudad capital, la mayor concentración (41.5\%).

La propia dinámica demográfica ha caracterizado una población especialmente joven en la sociedad peruana: el $46.8 \%$ constituye una población joven menor de 24 años; así también caracteriza una población con empleo informal del orden al 73.7\%. Por área de residencia, el empleo informal urbano asciende al $66.5 \%$. El ingreso promedio mensual proveniente del trabajo está alrededor de los 400 dólares americanos.

Desde las recomendaciones de la CEPAL en 1962 sucesivos gobiernos han intentado modernizar a la sociedad peruana aplicando el modelo de industrialización por sustitución de importaciones cuyos resultados han llevado a calificarlo de modernización frustrada.

El Compendio Estadístico Perú 2014 del Instituto Nacional de Estadística -INEI- es la fuente de los datos que hemos señalado. Ahí mismo se destaca en relación a la salud que un $17.5 \%$ de niños padece de desnutrición crónica (patrón de referencia OMS), ascendiendo al $32.3 \%$ en el área rural. Se registra un médico para 468 habitantes y una enfermera para 440; asimismo 15 camas hospitalarias por cada 10,000 habitantes. El $65.5 \%$ de la población cuenta con algún seguro de salud.

El INEI señala al 2013 un $23.9 \%$ de la población en situación de pobreza monetaria y un $4.7 \%$ en situación de pobreza extrema. Asimismo, el $38.8 \%$ respecto del total de la población de 15 y más años de edad han sido víctima de algún acto delictivo. De 268,018 casos registrados, el $67 \%$ son contra el patrimonio, tráfico ilícito de drogas, el $13 \%$ es contra la seguridad pública (que incluye tráfico ilícito de drogas, micro-comercialización, tenencia ilegal de armas, entre otros), el $11 \%$ es contra la vida, el cuerpo y la salud y el $5 \%$ contra la libertad (sexual, personal, de la intimidad, de domicilio). Al 2913 se reporta 831 casos registrados de acciones subversivas efectuadas por Sendero Luminoso (p.677)

En cuanto al acceso a tecnologías de información y comunicación el 82.5\% de hogares tienen al menos un televisor y en similar proporción se encuentran los hogares con al menos un miembro que tiene celular; el 32\% de hogares tiene al menos una computadora; el $39.2 \%$ de la población de 6 y más años de edad hace uso del servicio de internet.

En los últimos cinco años los diferentes medios de comunicación masivos, las redes sociales y las encuestas de opinión reportan como problemas sin visos de solución el incremento de la inseguridad ciudadana y la corrupción a diferentes instancias de gobierno, sea a nivel central, regional o local. 


\section{ANEXO No 3}

\section{REPRESENTACIONES SOBRE LA SOCIEDAD PERUANA}

Asumiendo con Jodelet (1989) que una representación social es una forma de conocimiento elaborado y compartido que concurre a la construcción de una realidad común a un conjunto social, se ha buscado identificar las producciones simbólicas, los significados y el lenguaje de las estudiantes de la UNIFÉ contenidos en sus opiniones en relación a la sociedad peruana, obteniéndose como resultado los mapas de representaciones siguientes:

\begin{tabular}{|cl|}
\hline REPRESENTACIÓN SOCIOLÓGICA & \\
\hline Sociedad con problemas DELINCUENCIALES & - inseguridad \\
\hline Sociedad DISCRIMINATORIA & - violencia \\
\hline & - pan de cada día \\
& - marginación \\
& - pobreza \\
& - exclusión \\
& - racismo físico y cultural \\
& - machismo \\
\hline Sociedad DIVERSA & - mixtura cultural \\
& - pluricultural \\
& - sin identidad \\
& - dividida \\
\hline
\end{tabular}

\begin{tabular}{|c|c|c|}
\hline \multicolumn{3}{|c|}{ REPRESENTACIÓN PSICOLÓGICA } \\
\hline MENTALIDAD & $\begin{array}{l}\text { - con conciencia } \\
\text { - abierta } \\
\text { - prejuiciosa } \\
\text { - estereotipada }\end{array}$ & $\begin{array}{l}\text { - sin conciencia de lo que pasa } \\
\text { - cerrada }\end{array}$ \\
\hline ACTITUDES & $\begin{array}{l}\text { - desconfianza: } r \\
\text { - individualismo: } \\
\text { - conformismo: } \\
\text { - facilismo: logra } \\
\text { - indiferencia } \\
\text { - trivialismo: chis } \\
\text { - pesimismo } \\
\text { - hipocresía }\end{array}$ & $\begin{array}{l}\text { ree en nadie } \\
\text { uno baila con su pañuelo } \\
\text { asar; nadie hace nada por salvar la situación } \\
\text { Incias con el menor esfuerzo } \\
\text { nediáticos }\end{array}$ \\
\hline
\end{tabular}


- dejado

- falta de empuje

- egoísta

- falta de ánimo

- no explota creatividad

\section{REPRESENTACIÓN AXIOLÓGICA}

PERCEPCIÓN GLOBAL DE VALORES - pérdida

- carencia/escasez

- crisis

- antivalores

PERCEPCIÓN ESPECÍFICA DE VALORES - respeto: ignorancia/pérdida/carencia

- honestidad: carencia

- solidaridad: pérdida

\begin{tabular}{|ll|}
\hline REPRESENTACIÓN ÉTICA & \\
\hline SOCIEDAD CORRUPTA & - manda el dinero \\
& - olvido de educación moral \\
& - lo bueno es malo \\
& - aumento de maldad \\
& - moral por los suelos \\
\hline \multirow{2}{*}{ LIBERTAD } & - sociedad de muchas libertades \\
& - conservadora \\
& - sin responsabilidad \\
\hline JUSTICIA & - injusticia \\
\hline
\end{tabular}

\section{REPRESENTACIÓN HISTÓRICO-TEMPORAL}

\begin{tabular}{|ll}
\hline Sociedad en CAMBIO & - en desarrollo \\
& - en todo aspecto: económico/social/cultural \\
& - proceso: positivo/negativo \\
\hline Sociedad que AVANZA & - crecimiento \\
& - progreso: tecnológico/industrial/cultural \\
& - evolución: mejora/empeora - diferencias abismales
\end{tabular}




\begin{tabular}{|l|l|}
\hline \multicolumn{2}{|l|}{ OTRAS REPRESENTACIONES } \\
\hline Con sentido POSITIVO & Con sentido NEGATIVO \\
\hline & -dañada por la economía \\
-tiene recursos & -caótica, desordenada, a la deriva \\
-es auténtica & -falta mucha información \\
-lucha por difundir conocimientos & -inestable \\
morales & -centralista \\
-hay más educación & -ignorancia de problemas sociales \\
-más importancia en inversión en & -clase politica no piensa en bien común \\
educación & -representantes aprovechan de nuestras \\
-gran potencial & necesidades \\
& -gobernados por personas de bajo nivel \\
& -programas de TV no ayudan a crecimiento \\
& moral, mental, espiritual \\
& -la contaminación es problema social \\
\hline
\end{tabular}

\begin{tabular}{|l|l|}
\hline REPRESENTACIONES DE PROPUESTAS FRENTE A PROBLEMAS \\
\hline ÉTICAS & - leyes más drásticas \\
& - mayor responsabilidad y esfuerzo \\
& - gente responsable y comprometida \\
& - hacer las cosas bien, sin dañar nadie \\
\hline POLÍTICAS & - gobierno debe poner más orden \\
& -saber elegir \\
& - necesidad de líderes \\
& - poner nuestra parte para cambiar \\
& - comenzar por uno mismo a cambiar \\
& - ser menos conformistas \\
PSICOLÓGICAS & - cambiar de mentalidad desde niño \\
& - aprender de los errores \\
& - debe haber oportunidades para todos \\
- desarrollo por educación \\
- conocer más nuestra cultura \\
- cambiar las costumbres para bien \\
- apoyo mutuo para desarrollar \\
- mejorar en educación, cultura \\
\hline
\end{tabular}




$$
\begin{aligned}
& \text { VALORATIVAS } \\
& \qquad \begin{array}{l}
\text { - ser más solidarios, honestos, buscar la verdad } \\
\text { - hacer respetar nuestros derechos } \\
\text { - aprender más sobre los valores y saber aplicarlos } \\
\text { - necesidad de cambio en sentido espiritual } \\
\text { - integrarse más } \\
\text { - inculcar valores a nuevas generaciones } \\
\text { - respetar y valorar a la mujer y la diversidad cultural }
\end{array}
\end{aligned}
$$

\section{ANEXO No 4 \\ SOBRE LA UNIVERSIDAD FEMENINA DEL SAGRADO CORAZÓN - UNIFÉ}

La UNIFÉ ofrece en la actualidad carreras profesionales y estudios de posgrado, así como estudios de complementación y de segunda especialidad. Las estudiantes que siguen una carrera profesional se consideran que están en el nivel de pregrado. En el segundo semestre del 2014 se registra 2,434 estudiantes matriculadas distribuidas en 12 carreras: Psicología, Educación Inicial, Educación Especial, Educación Primaria, Nutrición y Dietética, Traducción e Interpretación, Ciencias de la Comunicación. Arquitectura, Derecho, Ingeniería de Sistemas y Gestión de Tecnologías de Información, Administración de Negocios Internacionales y, Contabilidad y Finanzas. Las estudiantes de Psicología y de Derecho egresan después de haber aprobado 12 ciclos o semestres académicos; todas las demás completan 10 ciclos de estudio; en ambos casos los primeros cuatro ciclos corresponden al nivel de estudios generales y preespecialidad; los ciclos restantes corresponden a los estudios de formación profesional, reservándose, por lo general, los últimos ciclos para la práctica pre profesional intensiva.

La malla curricular de todas las carreras incluye asignaturas del área axiológica. Con algunas variantes propias por la extensión de los ciclos de formación, el área axiológica comprende los cursos de filosofía y teología (I y III ciclo), lógica (III), Doctrina Social de la Iglesia (IV), Antropología Filosófica (V o VII), Axiología (VIII) y Ética Profesional (IX).

Por lo general, en el segundo semestre académico las estudiantes siguen las asignaturas que corresponden a los denominados ciclos pares (II, IV, VI, VIII, X y XII).

En el presente estudio se ha aplicado la Encuesta sobre Espiritualidad a estudiantes de pregrado, excluyendo a las estudiantes de un programa especial integrado por mujeres con experiencia laboral (PROMEL) que siguen los estudios de Psicología (199), Nutrición y Dietética (49), Traducción e Interpretación (44) en horario diferenciado, en las noches, precisamente porque trabajan regularmente en el día y son de mediana edad.

Asimismo, se ha aplicado la encuesta a estudiantes matriculadas del III al IX ciclo, en el entendido que al tercer ciclo ya han realizado el $50 \%$ de los estudios generales y han experimentado las exigencias de los estudios de nivel superior y también conocen y participan de actividades de pastoral universitaria, de proyección y responsabilidad social y están en condiciones de elegir 
y ser elegidas en los órganos de gobierno de la Universidad, llámense Consejo de Facultad, Consejo Universitario y Asamblea Universitaria. De otro lado, se ha excluido de las encuestas a las estudiantes de las carreras de Contabilidad y de Ingeniería de Sistemas y gestión de tecnologías de información. A las primeras porque corresponden a una carrera nueva en la Universidad y a las segundas por no contar con matriculadas entre el tercer y noveno ciclos de estudio. También no han sido incluidas en el estudio las estudiantes de los ciclos X, XI y XII según el caso, en razón de las prácticas pre profesionales que generalmente se llevan fuera del claustro universitario.

Cabe mencionar que todas las estudiantes de la UNIFE desarrollan un perfil profesional sobre la base de una malla curricular que, además de los cursos de filosofía y teología del área axiológica, comprende también un conjunto de signaturas de las áreas de cultura general, investigación, preprofesional y profesional. Una estudiante del III ciclo ya ha seguido o está siguiendo cursos sobre Historia Universal, Historia de la Cultura Peruana, Realidad Nacional, Ecología, Sociología, Liderazgo Personal y Profesional, entre otros.

Las actividades educativas y de formación en la UNIFE responden a su MISIÓN de "procurar la formación integral de la persona, dotándola de una sólida capacitación científica, humanística, cristiana y tecnológica, que se traduzca en profesionales cabales, con vocación de servicio, en permanente búsqueda de la verdad y como agente de cambio e innovación en la solución de los problemas más acuciantes de la sociedad peruana y latinoamericana". 